\title{
EL PATRIMONIO DE LOS MARQUESES DE RAFAL (1639-1736)*
}

\author{
David BERNABÉ GIL \\ Universidad de Alicante
}

\begin{abstract}
Resumen
En el primer tercio del siglo XVII, un noble provinciano -D. Jerónimo Rocamorallevó a cabo un interesante proceso de acumulación patrimonial, integrado por bienes de naturaleza muy dispar, en el sur del reino de Valencia. En el presente artículo se analiza la trayectoria seguida por este patrimonio, constitutivo de la casa de Rafal, durante la centuria siguiente a su fallecimiento, así como las estrategias matrimoniales y las formas de gestión adoptadas por sus sucesores. Además de la evolución experimentada por los dominios señoriales, cobran especial relieve las adquisiciones de fincas en el realengo y la explotación de otros recursos, como es el caso del ganado mayor.
\end{abstract}

Palabras clave: Señorío, Rafal, Siglo XVII, Siglo XVIII, Nobleza, Valencia.

\begin{abstract}
In the first third of the 17 th century, a provincial nobleman $-\mathrm{D}$. Jerónimo Rocamora-carried out an interesting process of hereditary accumulation, comprising goods of very unlike nature, in the south of the kingdom of Valencia. In the present article the path followed by this wealth is analyzed, constituent of the house of Rafal, during the following century to its death, as well as the marital strategies and the methods of management adopted by its successors. Besides the experienced evolution by the lordships, they charge special relief the acquisitions of farms in the land of royal jurisdiction and the exploitation of other resources, as is the case of the greater cattle.
\end{abstract}

Keywords: Lordship, Rafal, 17th Century, 18th Century, Nobility, Valence.

\footnotetext{
* Este trabajo ha sido realizado en el marco del proyecto de investigación BHA2003-08362, financiado por el Ministerio de Ciencia y Tecnología y los fondos FEDER.
} 


\section{INTRODUCCIÓN}

Nobleza y señorío constituyen dos pilares esenciales sobre los que se levanta ese complejo entramado socioeconómico y políticoinstitucional que conocemos como Antiguo Régimen. Del protagonismo que ambos llegaron a adquirir en aquel periodo hay buenas muestras en la extensa bibliografía producida durante las últimas décadas, que, sobre todo la más reciente, ha tratado de llamar la atención, además, sobre la conveniencia de separar ambos elementos. Así -al margen de otras sugestivas propuestas de análisis concernientes a la sociedad estamental, como las interesadas en fenómenos relativos a la configuración y funcionamiento de las redes sociales- parece claro, por un lado, que no toda la nobleza ostentaba jurisdicciones señoriales; por otro, que, aquélla que sí lo hacía, también podía obtener rentas considerables de otras formas de dominio patrimonial ajenas al señorío. Por consiguiente, para una más adecuada comprensión de los mecanismos a través de los cuales una y otro fueron configurando su fisonomía, parece oportuno prestar una especial atención a la composición y a los procesos de formación de los patrimonios nobiliarios, así como a la gestión de los mismos y a las formas de extracción de la renta; y todo ello, en una perspectiva temporal que permita aprehender los distintos ritmos que van marcando la tendencia general'.

En esta línea, el presente trabajo, que enlaza directamente con otro anterior en el que se abordaba el proceso de gestación de un rico patrimonio nobiliario en una época relativamente tardía primer tercio del siglo XVII-, intenta mostrar la trayectoria seguida por el mismo durante la centuria siguiente ${ }^{2}$. Se trata del patrimonio constitutivo de la casa de Rafal, formada a partir del marquesado homónimo, que había creado D. Jerónimo Rocamora y Thomás en 1636, e integrada por un conjunto de propiedades

(*) Abreviaturas utilizadas en citas de archivos:

ACA: CA: Archivo de la Corona de Aragón: Consejo de Aragón

ACO: Archivo de la Catedral de Orihuela

AHN: Archivo Histórico Nacional

AHO: Archivo Histórico de Orihuela

AJPAAA: Archivo del Juzgado Privativo de Aguas del Azud de Alfaitamí

AMM: Archivo Municipal de Murcia

1. De la extensa bibliografía existente cabe destacar, por su relación con el enfoque y temática que aquí interesa, CATALÁ SANZ, Jorge Antonio: Rentas y patrimonios de la nobleza valenciana en el siglo XVIII, Siglo XXI, Madrid, 1995. En un contexto más amplio, resulta útil la síntesis de ARDIT LUCAS, Manuel (1993): Els homes i la terra del Pais Valencià (segles XVI-XVIII), Curial, Barcelona, 1993, 2 vols; asimismo, las apreciaciones de GIL OLCINA, Antonio: La propiedad señorial en tierras valencianas. Del Cenia al Segura, Valencia, 1979; PESET Reig, Mariano y GRAullera SANZ, Vicente: «Nobleza y señoríos durante el siglo XVIII valenciano», Estudios de Historia Social, $\mathrm{n}^{\circ}$ 12-13, 1980, pp. 245-281; RUIZ TORRES, Pedro: «La fi de la noblesa feudal al País Valencià», en VV.AA.: Terra, treball i propietat. Classes agràries i règim senyoral als Països Catalans, Crítica, Barcelona, 1986, pp. 166-185. Para el marco territorial más concreto en que se inscribe el caso aquí tratado, Millán Y GarCiA-VARELA, Jesús: Rentistas y campesinos. Desarrollo agrario y tradicionalismo politico en el sur del País Valenciano (1680-1840), Instituto de Estudios Juan Gil-Albert, Alicante, 1984.

2. BERNABÉ GIL, David: «La formación de un patrimonio nobiliario en el Seiscientos valenciano: el primer Marqués de Rafal», Revista de Historia Moderna, $n^{\circ}$ 5, Alicante, 1985, pp. 11-66. 
y señoríos que fueron expresamente vinculados dos años más tarde. Antes de disponer su carácter fideicomisario, estableciendo la linea sucesoria correspondiente, el mismo D. Jerónimo había reforzado otro vínculo, articulado en torno al señorío de Benferri, para el primogénito de su primer matrimonio, pero que, al discurrir en adelante por otra linea hereditaria distinta, no ocupará aquí nuestra atención.

El periodo ahora objeto de estudio abarcará, por tanto, desde el fallecimiento del primer marqués, en 1639 , y el momento en que, por defunción, sin hijos, de la cuarta titular, Da Jerónima Rocamora y Cascante, viuda de D. Jaime Rosell y Ruiz, en 1736, el mayorazgo vuelve a unirse a la rama de Benferri ${ }^{3}$. Se trata practicamente de una centuria durante la cual se sucedieron tres titulares -D. Gaspar, D. Juan y la mencionada $\mathrm{D}^{\mathrm{a}}$ Jerónima- al frente de la casa de Rafal, que llevaba anexa, además del marquesado del mismo nombre, la baronía de La Puebla y una amplia relación de bienes de diversa naturaleza.

El principal artífice del patrimonio cuyo seguimiento a lo largo de la mencionada centuria trataremos ahora de ofrecer, D. Jerónimo Rocamora y Thomas, había heredado el vínculo de Benferri, que transmitió al primogénito de su primer matrimonio -en cumplimiento de las claúsulas sucesorias originales-, no sin antes proceder a la colonización alfonsina de su núcleo constitutivo, posiblemente un antiguo señorío de jurisdicción civil prácticamente despoblado, que también es mencionado a veces como simple «heredad» de Benferri ${ }^{4}$.

Más allá de las significativas mejoras que esta actividad colonizadora comportaba en el vínculo de Benferri, D. Jerónimo no desaprovechó las oportunidades que le ofrecía el rico patrimonio heredado por su segunda esposa, $D^{a}$ María García de Lassa, para poner en práctica, también aquí, su fecunda actividad colonizadora. Aplicando una estrategia patrimonial y jurisdiccional que ya analicé en otro lugar, D. Jerónimo consiguió ampliar y reforzar las bases agrarias aportadas al matrimonio por D“ María y convertir la heredad de Rafal en señorio de jurisdicción alfonsina y cabeza de marquesado del mismo nombre.

Esta especie de obsesión por «fundar pueblos» sobre los cuales ejercer su dominio señorial se había manifestado previamente también con la obtención de la jurisdicción suprema, de mero y mixto imperio, sobre unas tierras desgajadas de una antigua baronía - La Daya Nueva- a cuya titularidad tuvo ocasión de acceder de forma especialmente ventajosa. Es así como surge la baronía de La Puebla, que conjuntamente con el marquesado de Rafal, constituirán el fundamento de un segundo vínculo, creado por

3. Pardo y Manuel de Villena, Alfonso: El Marqués de Rafal y el levantamiento de Orihuela en la Guerra de Sucesion (1706), Madrid, 1910; BARÓN DE Finestrat: Nobiliario alicantino, Instituto de Estudios Alicantinos, Alicante, 1983, p. 270. Utilizo sólo los apellidos primeros de los progenitores, que no necesariamente han de coincidir, en cuanto al orden establecido, con los que se usaban efectivamente, a tenor de las disposiciones hereditarias contenidas en las constituciones de vinculos y fideicomisos.

4. Esta información y la que sigue, salvo indicación en contrario, procede de BERNABé GIL, David: «La formación..., , donde podrán encontrarse los detalles y referencias pertinentes. 
disposición testamentaria en 1638 y destinado al primogénito de su segundo matrimonio y a la linea sucesoria correspondiente.

Tras el fallecimiento de $\mathrm{D}$. Jerónimo al año siguiente, por tanto, el vínculo de Benferri y el de Rafal correrán por lineas sucesorias distintas, hasta que, un siglo más tarde -en 1736-, ambos vuelven a confluir en un mismo heredero: D. Jaime Rocamora y Cascante, quien una década antes había accedido ya a la titularidad de Benferri y ahora reclamó con éxito la de Rafal al haber fallecido sin descendencia directa su última titular, $\mathrm{D}^{\mathrm{a}}$ Jerónima Rocamora. A partir de entonces la casa de Rafal incluirá ya siempre ambos mayorazgos, al tiempo que sus titulares, mediante ventajosos matrimonios, irán entroncando con casas castellanas y ascendiendo en el escalafón nobiliario; hasta obtener, en 1790, la Grandeza de España de primera clase ${ }^{5}$.

Por consiguiente, el patrimonio nobiliario cuya trayectoria trataremos de analizar aquí, para el periodo mencionado, es el integrado originalmente por la herencia recibida por el primogénito del segundo matrimonio de D. Jerónimo, D. Gaspar Rocamora García de Lassa, II marqués de Rafal a partir del 13 de agosto de 1639, así como las ampliaciones de que fue objeto a lo largo del tiempo, tanto en concepto de mejoras del vínculo, con las incorporaciones patrimoniales subsiguientes, como de bienes de libre disposición. La composición de esta herencia, que denominaremos también, indistintamente, como «la casa de Rafal», aunque descansaba en los bienes expresamente vinculados en el testamento de 1638, abarcaba asímismo otros que, a pesar de catalogarse como de libre disposición, solían pasar en su integridad a los sucesivos hereus.

\section{HERENCIA Y PATRIMONIO}

Esta estrategia, que facilitó enormemente el proceso de acumulación patrimonial, se vió claramente favorecida por la escasa capacidad procreadora de los sucesivos marqueses de Rafal. Así, al no haber hijos del matrimonio contraído en 1645 por D. Gaspar con $D^{a}$ Maria Manuela Fernández Valenzuela y Vázquez, la herencia pasará íntegramente a su hermano D. Juan en 1666 -casado con $D^{a}$ María Luisa Cascant y Roda. Y, tras el fallecimiento de éste en 1691, le sucederá la primera de sus dos hijas, $\mathrm{D}^{\mathrm{a}}$ Jerónima, quien tampoco tuvo descendencia de su matrimonio con D. Jaime Rosell y Ruiz, mientras que su única hermana fallecía soltera ${ }^{6}$.

Ciertamente, la numerosa prole del fundador del marquesado, que llegó a procrear seis hijos del primer matrimonio y otros cinco más del segundo, pudo haber sido $a$ priori motivo de disgregación de una parte del cuantioso patrimonio que fue capaz de acumular durante su activa vida. Sin embargo, las obligaciones que recayeron sobre el primogénito, D. Gaspar, de atender los derechos hereditarios de sus hermanos fueron asumidas sin excesivo riesgo para la integridad de la herencia recibida. Y ello se

5. VILAR RAMíREZ, Juan Bautista: Orihuela, una ciudad valenciana en la España Moderna, Caja de Ahorros de Alicante y Murcia, Alicante, 1982, vol. I, p. 244; Millán y GARCía VARElA, Jesús: Rentistas y campesinos..., p. 322

6. BARÓN de Finestrat: Nobiliario....., pp. 265-268. 
debió, en gran medida, a una eficaz combinación del azar con la capacidad previsora del testador.

Así, de los cuatro hermanos maternos de D. Gaspar, las dos mujeres - $\mathrm{D}^{\mathrm{a}}$ Catalina, y $\mathrm{D}^{\mathrm{a}}$ Inés-recibieron legados que, por su naturaleza, apenas llegaron a afectar a la conservación del patrimonio recibido por aquél. La primera, beneficiaria de una pensión vitalicia de 150 libras anuales para alimentos, falleció soltera; mientras que para la dote matrimonial de $\mathrm{D}^{\mathrm{a}}$ Inés -que habría de casar en 1649 con D. Vicente Ruiz y Rosell- se destinaron en un principio 4.000 libras, que fueron incrementadas en otras 2.000 por la marquesa viuda $D^{a}$ María, en su último codicilo de 1645 , poco antes de fallecer ${ }^{7}$ y que se hicieron efectivas en más de un centenar de cabezas de ganado mayor, 27 deudas por cobrar y algunos objetos de oro y plata ${ }^{8}$.

En cuanto a los varones, D. Jaime y D. Juan, recibirían 10.000 libras cada uno, en su mayor parte en fincas ubicadas en la huerta de Orihuela, que D. Jerónimo, su progenitor, había ido adquiriendo a diversos particulares y dejado al margen del vínculo constituído. Para hacer efectiva la herencia del primero se asignaban 8 parcelas, con una extensión total de 109 tahúllas de huerta; para el segundo, dos fincas de 65 y 72 tahúllas, respectivamente? ${ }^{9}$. Ahora bién, aunque estos legados pudieron haberse traducido a priori en una detracción significativa en el patrimonio rústico acumulado por D. Jerónimo, la supuesta egresión no llegó a materializarse de forma irreversible, pues D. Jaime permanecía soltero hacia 1653 , cuando fue asesinado por una cuadrilla de bandidos ${ }^{10}$; y D. Juan, que sobrevivió largamente al anterior, acabó heredando el marquesado al fallecer sin hijos su hermano mayor, D. Gaspar, en 1666.

En consecuencia, puesto que los legados de quienes no contraían matrimonio o fallecían sin descendencia revertían a la línea prinicipal, prácticamente no llegaron a producirse egresiones definitivas reseñables de la misma en todo el periodo considerado. Sí se detecta, en ocasiones, la desaparición de algunas pequeñas fincas entre el patrimonio de la casa de Rafal; pero lo más probable en tales casos es que fueran consecuencia de enajenaciones o permutas. En sentido contrario, fueron muchas y variadas -como se verá más adelante- las incorporaciones patrimoniales que a lo largo del tiempo engrosaron la casa de Rafal.

7. AHN: Consejos, Leg. 22.315, ff. 114-138v; copia del testamento de D. Jerónimo Rocamora y Thomas y Da María García de Lassa, Marqueses de Rafal, ante el notario de Orihuela, Ginés Martínez, en 29 de enero de 1638; AHO: Protocolos de Juan Liñán, 1644-1645, Codicilo de Da María García de Lassa, escrituras de 13 y 17 de mayo de 1645 .

8. AHO: Protocolos de Bertomeu Roig, 1649; cartas matrimoniales, en 3 de mayo de 1649. El desglose es el siguiente: 80 cabezas de ganado vacuno, estimadas en 2.610 libras; un número indeterminado de «fruits de egues, entre machos y mules»), por un valor de 1.000 libras; otras 1.1624 libras en 27 obligaciones y deudas por cobrar a particulares; finalmente, objetos de oro y plata, valorados en 766 libras.

9. AHN: Consejos, Leg. 22.315, ff. 114-138v; copia del testamento de D. Jerónimo Rocamora y Thomas y $D^{4}$ Maria García de Lassa, Marqueses de Rafal, ante el notario de Orihuela, Ginés Martínez, en 29 de enero de 1638; AHO: Protocolos de Juan Liñán, 1644-1645, Codicilo de Da María García de Lassa, escrituras de 13 y 17 de mayo de 1645 .

10. ACA: CA: Leg. 685, exp. 49/1-5. 
Pero antes de adentrarnos en el análisis de la trayectoria seguida importa recordar ahora su composición justamente en la situación de partida; esto es, a la muerte del primer marqués. Si por algo se había distinguido D. Jerónimo Rocamora en su estrategia patrimonial, había sido por la diversificación de sus inversiones, de modo que, además de los ya mencionados señoríos de La Puebla y de Rafal, el vínculo de este nombre incluía también otros bienes, a los que se añadían los de libre disposición. Entre los primeros -como podrá apreciarse en el CUADRO I- destaca la casa principal - o solariega- en la ciudad de Orihuela, otra casa con su huerto anexo -denominado Las Palmeras-, una zona de almarjales anexos a la Puebla, cuyo dominio útil le fue concedido a perpetuidad por la ciudad de Orihuela -denominada la Majada Vieja-, una heredad de huerta también anexa a La Puebla -denominada la Era Alta-y algunos censales sobre instituciones importantes, como el consistorio oriolano y la comunidad de regantes del Azud de Alfeitamí. Entre los segundos, cobran especial relieve la numerosa cabaña ganadera -yeguar y caballar-, pero también un total de 10 pequeñas y medianas fincas rústicas de regadío diseminadas por la huerta del Bajo Segura, otra de mayor tamaño anexa a Rafal -denominada de Tell-, una cañada de secano en el campo de las Salinas y una impresionante nómina de obligaciones crediticias o deudas a corto plazo de las que era acreedor. En total, un patrimonio diversificado en su naturaleza y gestación, con una valoración económica de dificil cuantificación, pero que cabe situar entre las más grandes fortunas nobiliarias del sur valenciano ${ }^{11}$.

\section{CUADRO I}

Composición del patrimonio constitutivo de la Casa de Rafal (1639)

\section{Vínculo de Rafal}

Marquesado de Rafal unas 1.500 tahúllas de huerta

Baronía de La Puebla 2.010 tahúllas de huerta

La Majada Vieja. unas 2.000 tahúllas de almarjales

Heredad La Era Alta 200 tahúllas de huerta

Casa prinicipal en Orihuela

Casa-huerto Las Palmeras

Censal sobre la ciudad de Orihuela 25.000 libras de propiedad

Censal sobre el Azud de Alfeitamí 5.074 libras de propiedad

Bienes de libre disposición

Heredad de Tell 330 tahúllas (huerta)

Heredad en la Puerta de Murcia 65 tahúllas (huerta)

Heredad en las Correntías 72 tahúllas (huerta)

11. BERNABÉ GIL, David: «La formación...». 


\section{Bienes de libre disposición}

8 parcelas de morerales 109 tahúllas (huerta)

Cañada en Las Salinas campo

3 censales 1.400 libras de propiedad

Préstamo a cambio al Marqués de los Vélez 14.000 libras

Préstamo a cambio a la junta patrimonial de Elche. 1.500 libras

502 obligaciones a particulares 33.034 libras

Vaquería 306 cabezas

Yeguada 160 cabezas

Ovejas 1.050 cabezas

Borregos 645 cabezas

Cerdos 163 cabezas

Fuente: ACO: Protocolos de Ginés Martinez, 1639; inventario de 7 de novimebre de 1639

\section{MATRIMONIO Y PATRIMONIO}

$\mathrm{Si}$, además de la vinculación, la fatalidad de una descendencia poco prolija evitó egresiones patrimoniales de relieve en el núcleo original del marquesado-incluidos los bienes libres-, la política matrimonial desplegada por los titulares del mismo determinó, en general, una progresiva ampliación, aunque no de un modo uniforme u homogéneo. Atendiendo a las dotes aportadas por los consortes de los sucesivos herederos del título de Rafal, es posible detectar algunas diferencias significativas que afectan tanto a la cuantía como a la composición de los bienes llevados a los respectivos matrimonios. Y estas diferencias no son del todo ajenas a las bases sociales donde se acudió en busca de cónyuges apropiados a la categoría social y económica de los marqueses.

Para su matrimonio con D. Gaspar, en 1643, Da María Manuela Valenzuela, vecina de la ciudad de Murcia, como heredera y sucesora en el mayorazgo de Cinco Alquerías, aportó una parte de las rentas procedentes de dicho vínculo, integrado por el señorío del mismo nombre, casa principal en Murcia, y unas cañadas de tierra de secano en San Pedro del Pinatar. En las cartas matrimoniales correspondientes no se especificaba el valor global de la dote, pero sí las cantidades a detraer cada año para alimentos de su padre y titular del mayorazgo -D. Pedro Valenzuela Fajardo- y de su madre-D Josefa Vázquez Fajardo-, consistentes en 400 ducados y la mitad de la parte restante de la renta global una vez deducidos los dos censos -por valor de 3.300 ducados de capital- que recaían sobre el vínculo ${ }^{12}$. A partir de estos datos resulta imposible cuantificar, siquiera de forma aproximada, el valor del mismo; pero, en una estimación a la baja, y sin contar el inmueble urbano - cuya mitad, según capitulaciones matrimoniales, debía servirles de residencia- es casi seguro que llegara a superar, quizá ampliamente, los

12. AHN: Consejos, Leg. 22.004, exp. $\mathrm{n}^{\circ} 9$, sin fol. Copia de capítulos matrimoniales, ante el notario de Madrid Juan Fernández de Otero, en 26 de octubre de 1643. 
25.000 ducados. Más adelante, tras el fallecimiento de sus progenitores, al tomar posesión del mayorazgo, $\mathrm{D}^{\mathrm{a}}$ María Manuela debió incrementar su patrimonio con los bienes muebles que, como única heredera, albergaba la casa principal de la ciudad de Murcia, más la otra mitad del inmueble, así como los frutos, aparejos y ganado de labranza inventariados - sin valorar- en el señorío de Cinco Alquerías. En cualquier caso, tomados en conjunto, el valor patrimonial de los bienes de la esposa de D. Gaspar quedaba muy alejado de las más de 100.000 libras en que es posible calcular el de éste último, según cabe deducir de varias estimaciones ${ }^{13}$

Pero, más que la cuantía de los bienes de su noble esposa, o incluso de su carácter señorial, en la elección matrimonial de D. Gaspar debió pesar de forma no menos decisiva su condición de única heredera $y$, en consecuencia, la inexistencia de hermanos con derechos hereditarios que atender. La fortuna quiso, sin embargo, que, al no haber hijos de este matrimonio, el patrimonio acabara por alejarse de la linea de Rafal. El mayorazgo y señorío de Cinco Alquerías, cuya titularidad ostentaron los marqueses de Rafal durante varios años, retornó a la linea murciana de los Vázquez Fajardo, efectivamente, tras el fallecimiento de D. Gaspar, en 1666. Primeramente, en la persona de su viuda, que, despojada del título de Rafal en beneficio de su cuñado, D. Juan Rocamora, debió transmitirlo posteriormente a un primo suyo, según las reglas de primogenitura y masculinidad propia de los mayorazgos, y con el que pensó encontrar acomodo cuando -según confesaba en 1676- decidió regresar definitivamente a la ciudad de Murcia ${ }^{14}$.

Habiendo accedido a la titularidad de Rafal a una edad no demasiada temprana para su estado de soltería -en torno a los 40 años-, D. Juan apenas tardó 9 meses en contraer esponsales. Eligió para ello a una viuda rica, de estado noble, pero sin título señorial. $D^{a}$ Luisa Cascant y Roda, que había casado en primeras nupcias con un primo hermano, el caballero Pere Cascant y Ruiz, y era hija del dean de la catedral de Orihuela, el Dr. D. Bertomeu Cascant García de Lasa, aportaba al matrimonio bienes valorados en 34.898 libras, 5 sueldos y 8 dineros, con unas cargas a descontar, en concepto de censales a carta de gracia, de 2.485 libras de propiedad ${ }^{15}$. El desglose de este patrimonio revela, una vez más, que era la propiedad de la tierra la fuente principal del que se nutría, pues - tal como revela el CUADRO II- entre las cinco fincas que lo integraban, con un total de 1.200 tahúllas de riego y 1.050 de secano, sobrepasaban el 90 por ciento del valor global. Pero tampoco en este caso, aunque bien pudiera superar la de la anterior marquesa consorte, la dote de $\mathrm{D}^{\mathrm{a}}$ Luisa conseguía aproximarse a la aportación del heredero de Rafal.

13. Para dicho cálculo se ha partido de la valoración pormenorizada realizada por su sucesor, al tomar posesión del patrimonio en 1666. Se han descontado las propiedades adquiridas con posterioridad a 1643, y se han añadido otras que en 1667 no fueron estimadas por estar bajo litigio, pero que ya constaban en aquella fecha.

14. AHO: AHN: Consejos, Leg. 22.004, exp. $n^{\circ} 9, \sin$ fol.

15. AHO: Protocolos de Bertomeu Roig, 1667, cartas matrimoniales, de 29 de mayo de 1667. 


\section{CUADRO II \\ Bienes aportados al matrimonio por $\mathrm{D}^{a}$ Luisa Cascant y Roda (1667)}

Heredad La Media Legua, de 190 tahúllas huerta 3.158 libras 80 tahúllas de secano (Foia del Cabeco). 160 libras

70 tahúllas de secano (Cabezo de Hurchillo). 20 libras

Heredades Casa Grande y Caseta de Cascante, de 1.010 tahullas huerta, en Acequia de Molina 22.680 libras

Heredad Torre y dehesa de Cascante, de 1.000 tahúllas 2.500 libras

Casa en Orihuela .1 .000 libras

Dinero en efectivo 1.500 libras

Enseres, muebles, ropa, joyas 3.880 libras

Censales con que están gravadas las propiedades. 2.485 libras TOTAL NETO 32.413 libras

Fuente: AHO: Protocolos de Bhertomeu Roig, 1667, cartas matrimoniales, de 29 de mayo de 1667.

\section{CUADRO III}

Bienes aportados al matrimonio por D. Juan Rocamora García de Lassa (1667)

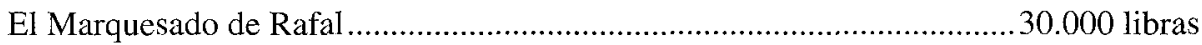

La Baronía de la Puebla, con los almarjales anexos .................................40.000 libras

Heredad de D. Felipe Ocaña, de 700 tahúllas huerta ................................ 10.000 libras

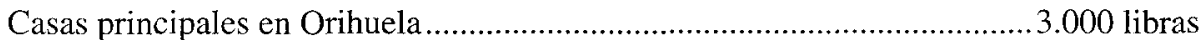

Huerto cercado Las Palmeras..................................................................2.000 libras

Heredades de Tell, Arques y Les Añores, todas huerta ............................20.000 libras

Censal que le responde la ciudad de Orihuela ............................................. 7.500 libras

Censal que le responde el Azud de Alfeitami ..........................................5.200 libras

Ganado mayor, joyas, obligaciones, etc.................................... inventariado en 1666 TOTAL BIENES VALORADOS ..........................................................117.700 libras

Fuente: AHO: Protocolos de Bertomeu Roig, 1667, cartas matrimoniales, de 29 de mayo de 1667.

$\mathrm{Y}$ es que, en efecto, el valor estimado de las tierras, casas y señoríos de D. Juan, sin contar la valiosa cabaña ganadera, créditos y joyas -como bienes en litigio con su cuñada viuda, $\mathrm{D}^{\mathrm{a}}$ María Manuela- alcanzaba ya por entonces las 105.000 libras de propiedad. Si a ello sumamos las 13.200 libras del principal de dos censales - de 7.500 y 5.700 libras, respectivamente- y en torno a unas 17.000 libras, que debían valer las más de 800 cabezas de ganado mayor, el patrimonio total del heredero de Rafal 
pudo aproximarse facilmente a las 140.000 libras en el momento de hacerse cargo del mismo ${ }^{16}$.

El valor de los bienes llevados por D. Juan al matrimonio caudriplicaba, por tanto, el de su esposa. Pero, a diferencia del destino seguido por la dote de su predecesora en la titularidad del marquesado -como consorte-, la mayor parte del patrimonio aportado por $\mathrm{D}^{\mathrm{a}}$ Luisa sí conseguiría integrarse finalmente en los dominios de la casa de Rafal. Así, el único vástago superviviente del matrimonio contraído en 1667 por D. Juan y $\mathrm{D}^{\mathrm{a}}$ Luisa, la primogénita y heredera universal del título de Rafal, $\mathrm{D}^{\mathrm{a}}$ Jerónima, aunó en 1691 la titularidad de los bienes dejados por sus dos progenitores. Solo cuatro meses más tarde del fallecimiento del marqués, la heredera contraía matrimonio con otro rico hacendado oriolano, el noble D. Jaime Rosell y Ruiz, señor de Benejúzar y poseedor de un valioso mayorazgo, integrado por nueve grandes fincas rústicas de regadío y de secano -además del núcleo señorial- que, conjuntamente con los bienes libres aportados - una casa, un horno, una finca rústica y tres molinos-, alcanzaba las 228.000 libras. Para entonces, también los bienes constitutivos de la herencia de Rafal habían incrementado notablemente su valor, al haber añadido D. Juan al vínculo originario -por disposición testamentaria de $169 l$ - las adquisiciones realizadas durante su vida; de modo que la valoración del patrimonio aportado por $\mathrm{D}^{\mathrm{a}}$ Jerónima, para su matrimonio con D. Jaime, se situó en unos niveles similares, pues a las 188.028 libras en que fue estimado el mayorazgo de Rafal y los bienes muebles había que añadir, en concepto de parafernales y extradotales, la herencia de su madre, $D^{a}$ Luisa Cascante, que -como ya se dijo- se había aproximado a las 35.000 libras años atrás ${ }^{17}$.

\section{CUADRO IV}

Bienes aportados al matrimonio por Da Jerónima Rocamora y Cascante (1691)

\section{Bienes vinculados}

El Marquesado de Rafal 30.000 libras

La Baronía de La Puebla, con los almarjales anexos 40.000 libras

Heredad de D. Felipe Ocaña, de 600 tahúllas de huerta 10.000 libras

170 tahúllas de huerta, contiguas a D. Felipe 527 libras

Heredad La Era Alta, de 160 tahúllas huerta 1.000 libras

Heredad de Arques, de huerta 4.000 libras

Heredad de Tell, de huerta 1.200 libras

Heredad de Saavedra, de huerta. 6.000 libras

Heredad de Guardalacapa ( $D^{a}$ Ines), de 600 thas huerta. 8.000 libras

16. Ibidem. El valor real debió ser aun mayor, pues en el inventario realizado tras la muerte de D. Gaspar, según escrituras de 1, 2, 3, 4, 13, 25 y 27 de septiembre, 24 de octubre y 28 de noviembre de 1666 (AHO: Protocolos de Bhertomeu Roig, 1660), se añaden otros bienes, incluídas algunas fincas, que también eran propiedad de los marqueses y, tras los pleitos con $\mathrm{D}^{a}$ María Manuela, continuaron formando parte de la herencia.

17. ACO: Protocolos de Andrés Ximenez, 1691, ff. 258 y ss. 
Heredad de les Añores, de 200 tahúllas huerta ................................... 4.000 libras

Heredad de Casa Nova, de huerta ...................................................... 3.000 libras

Huerto cercado (Las Palmeras) .......................................................... 3.000 libras

9 parcelas de huerta, de 228 tahúllas en total....................................... 6.740 libras

Cañada en la Matanza, de secano...................................................... 2.000 libras

Cañada en las Salinas, de secano ..................................................... 4.000 libras

Cañada de les Safurdes, de secano.................................................. 1.000 libras

Cañada La Cova Forta, de secano ..................................................... 1.500 libras

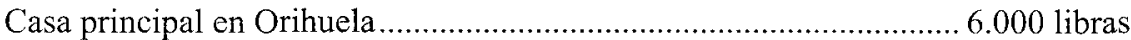

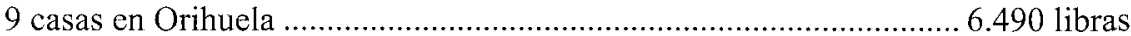

Casa en Almoradí ............................................................................. 1.000 libras

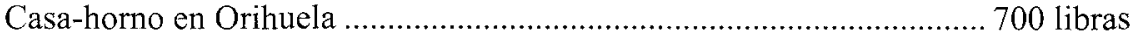

Censal obre la ciudad de Orihuela .................................................... 7.500 libras

Censal sobre el Azud de Alfeitami................................................... 5.200 libras

Bienes muebles y semovientes

1.168 cabezas de ganado mayor.....................................................22.020 libras

Bienes muebles .......................................................................16.251 libras

TOTAL BIENES VALORADOS ………............................................ 188.028 libras

Bienes parafernales y extradotales inestimados

Heredad Casa Grande de Cascante

Heredad Caseta de Cascante

Heredad de la Media Legua

Cañada Dehesa de Cascante

Cañada de 70 tahúllas secano

80 tahúllas de secano

Casas en Orihuela

8 pares de mulos y 10 bueyes, «per a la llauro de les cañades»

Carruajes, mulas y caballos y otros enseres

VALOR APROXIMADO

32.000 libras

TOTAL BIENES VALORADOS E INESTIMADOS

220.000 libras

Fuente: ACO: Protocolos de Andrés Ximenez, 1691; ff. 258 y ss.; cartas matrimoniales

A partir de 1691, por tanto, los marqueses de Rafal se hicieron cargo de -y tuvieron que gestionar- un patrimonio conjunto valorado en torno a unas 448.000 libras; lo que les situaba ya entre las grandes fortunas nobiliarias del Reino de Valencia. Mas esta concentración patrimonial no habría de resultar definitiva pues, al carecer de descendencia el matrimonio, tras el fallecimiento de $\mathrm{D}$. Jaime en 1727, el vínculo de Benejúzar pasó a la linea de los Rosell --en los derechohabientes de los herederos de su hermana, 
$\mathrm{D}^{a}$ Isabel ${ }^{18}$ - . Por su parte, el de Rafal era heredado en 1736 por D. Jaime Rocamora y Cascante, primo de la marquesa difunta, y sobre el cual, unos años más tarde -en 1739-, recaería también el vínculo de Benferri. De este modo, volvían a confluir en una misma linea los dos mayorazgos - con sus mejoras y ampliaciones-constituídos justamente un siglo atrás por el primer marqués de Rafal, D. Jerónimo Rocamora y Thomas.

\section{CUADRO V}

Bienes aportados al matrimonio por D. Jaime Rosell y Ruiz (1691)

\section{Bienes vinculados}

El señorío de Benejúzar 100.000 libras

Heredad de Rubes, de 150 thas huerta y 300 secano. 5.650 libras

Heredad de Rambla, de 500 thas huerta. 8.300 libras

Heredad del Pi, de 600 thas huerta 4.800 libras

Heredad Casa Grande, de 800 thas huerta 11.000 libras

Heredad la Barraqueta, de 400 thas huerta 3.750 libras

Heredad de 300 thas huerta. 7.500 libras

Cañada Rambla de D. Jaume, de secano. 500 libras

Cañada La Somada, de secano 600 libras

Heredad de Algorfa, de regadío y secano. 30.000 libras

TOTAL BIENES VINCULADOS 177.600 libras Bienes libres

1 casa

2 molinos harineros

1 molino arrocero

1 horno

40 tahúllas de huerta

TOTAL BIENES LIBRES 50.400 libras TOTAL 228.000 libras

Fuente: ACO: Protocolos de Andrés Ximenez, 1691; ff. 258 y ss.; cartas matrimoniales

Durante esa centuria, algunos de los marqueses de Rafal habían llegado a ostentar también la titularidad de otros vínculos señoríales -Cinco Alquerías, Benejúzar-, merced a las estrategias matrimoniales practicadas. Pero, finalmente, la biología impuso su ley, y las posibilidades de concentración patrimonial se vieron truncadas por la escasa capacidad reproductora de esta nobleza. En consecuencia, aunque las estrategias matrimoniales parecen presididas por la idea de enlazar con unigénitos de la nobleza señorial, las dificultades para gestar herederos se convirtió en un factor decisivo que,

18. AHO: Protocolos de Gregorio Regil, 1727; ff. 8-24v, testamento otorgado por D. Jaime Rosell, el 8 de abril de 1727. 
por un lado, impidió una mayor concentración patrimonial, determinando la separación de vínculos que, de otro modo, pudieron haberse concentrado en una misma linea sucesoria. Pero, por otro lado, y en sentido contrario, contribuyó a mantener la integridad de las herencias, al liberar parcialmente a los sucesores de atender las cargas que representaban las legítimas y otros derechos de los segundones.

Con todo, tampoco puede afirmarse que las transmisiones hereditarias en favor de un solo heredero afectaran íntegramente a la totalidad del patrimonio personal. Las disposiciones testamentarias de los sucesivos titulares de Rafal y de sus correspondientes cónyuges, en efecto, solían contener obligaciones pías y legados, a detraer de los bienes libres, que a veces alcanzaron cierto relieve. Además del coste de las numerosas misas ordenadas para la salvación de las respectivas almas, distribuidas entre varias instituciones religiosas -6.000 misas en el caso de D. Gaspar, 2.300 en el de D. Juan y 3.000 en el de $\mathrm{D}^{\mathrm{a}}$ Jerónima-, un buen número de conventos se beneficiaron de la piedad de los marqueses, en cumplimiento de sus últimas voluntades, también en forma de limosnas especiales ${ }^{19}$. Algo menos de importancia asumieron las gratificaciones destinadas a individuos que habían destacado en el servicio a la casa señorial. Pero fueron algunos familiares con los que debieron anudarse intensos lazos sentimentales quienes resultaron especialmente favorecidos, sobre todo en caso de no haber descendencia directa. Así, en el último testamento ordenado por $\mathrm{D}^{\mathrm{a}}$ Jerónima, pocas semanas antes de fallecer, en 1736, se cedían dos fincas de secano - con un total de 1.070 tahúllas- a una sobrina, mientras que el usufructo de los cuantiosos bienes libres restantes pasaba, de forma vitalicia, al canónigo de la iglesia metropolitana de Valencia, el noble D. Francisco Boil de Arenós ${ }^{20}$. La generosa actitud de $\mathrm{D}^{\mathrm{a}}$ Jerónima para con algunos de sus deudos y familiares se explica, pues, en gran medida, por la inexistencia de frutos de su matrimonio. Ciertamente, esta circunstancia también había concurrido anteriormente en el caso de D. Gaspar, a quien sobrevivieron otras dos hermanas -además del heredero del título. Pero, al venir gozando ya éstas $-\mathrm{D}^{\mathrm{a}}$ Ines y $\mathrm{D}^{\mathrm{a}}$ Catalina- de las asignaciones económicas establecidas por disposiciones testamentarias de sus progenitores -los primeros marqueses de Rafal-, el testador consideró que era suficiente con traspa-

19. AHO: Protocolos de Bertomeu Roig, 1666; testamento de D. Gaspar Rocamora García de Lassa, en 26 y 27 de agosto de 1666; AHN: Consejos, Leg. 22.315, $1^{\text {a }}$ pieza, ff. 139-153v.: copia del testamento de D. Juan Rocamora Garcia de Lassa, en 25 de marzo de 1691; AHO: Protocolos de Bautista Alemán, 1735; testamento de $D^{a}$ Jerónima Rocamora y Cascante, el 2 de febrero de 1736, y codicilo de la misma, en 25 de febrero de 1736.

20. AHO: Protocolos de Bautista Alemán, 1735; testamento de $\mathrm{D}^{4}$ Jerónima Rocamora y Cascante, el 2 de febrero de 1736, y codicilo de la misma, en 25 de febrero de 1736. Las dos fincas legadas a su sobrina, $D^{a}$ María Rosell y Carrasco, esposa de D. Luis Juan de Torres y Centelles, vecino de la ciudad de Valencia, eran la heredad Torre y dehesa de Cascante, de 1.000 tahúllas de secano, y otra cañada de 70 tahúllas. A D. Francisco Boil de Arenós, canónigo de la iglesia metropolitana de Valencia, legaba el usufructo vitalicio de las heredades Casa Grande y Caseta de Cascante, con 1.200 tahúllas de secano entre ambas, y una casa en la calle de Santiago de Orihuela, que pasarían tras su muerte al sucesor en el vínculo de Rafal, integrándose en el mismo. 
sar al hereu, D. Juan, las obligaciones allí ordenadas, sin modificaciones sustanciales, toda vez que, por otro lado, dejaba viuda con derechos y necesidades que atender ${ }^{21}$.

Sin contar las mandas pías y legados ordenados por los marqueses consortes en sus correspondientes testamentos -que, por lo general, afectaban a sus respectivas dotes-, las detracciones del volumen patrimonial acumulado por los titulares de Rafal no alcanzaron valores de gran relieve; lo que, unido a otras circunstancias ya comentadas, coadyuvó a la consolidación del patrimonio y aun a un significativo crecimiento del mismo en cada nueva generación. Pero, más allá de su estimación en metálico -de la que ya se han ofrecido cifras globales para 1645, 1666 y 1691-, interesa conocer también su composición y la trayectoria seguida por los diversos bienes que lo integraban, así como las modalidades de gestión y explotación de cada uno de ellos.

A tal fin y haciendo siempre abstracción del patrimonio aportado por los consortes que, tras su fallecimiento, volvió a salir de la casa de Rafal, se establecerá una tipología que nos permita emprender el análisis diferenciado de las diversas componentes patrimoniales y de su evolución secular, distinguiendo los siguientes apartados: señoríos, heredades y fincas de realengo, casas e inmuebles urbanos, cabaña ganadera y censales y créditos. Aun siendo conscientes de la importancia que, desde el punto de vista económico y de la ostentación social, tuvieron determinados bienes muebles y semovientes, como las joyas, objetos artísticos, enseres domésticos de todo tipo, carruajes, esclavos, etc., todos ellos quedarán fuera de nuestro análisis, pues, a la escasa información que presentan las fuentes sobre estas formas de riqueza, se añade nuestro mayor interés por otro tipo de recursos productivos de base agraria y pecuaria.

\section{LA ACUMULACIÓN DEL PATRIMONIO AGRARIO: RITMOS Y MODALIDADES}

Comenzando, pues, por la propiedad señorial, cabe recordar que las dos únicas incorporaciones producidas a lo largo de la centuria considerada a la casa de Rafal -integrada por el marquesado homónimo y la baronía de La Puebla- no llegaron a resultar definitivas, correspondiendo, respectivamente, al señorío de Cinco Alquerías -entre 1645 y 1666 - y al de Benejúzar -entre 1691 y 1727 . Más notable y duradero fue, en cambio, el incremento de las fincas ubicadas en el realengo. Si en 1639/45 formaban parte del patrimonio familiar un total de 12 fincas de huerta, con una extensión total de 773 tahúllas de regadío, otra de almarjales, con unas 2.000 , y una cañada de campo, de extensión indeterminada, pero inferior a las 2.000 tahúllas, solo medio siglo más tarde el incremento puede calificarse de espectacular ${ }^{22}$. En 1691, en efecto, son ya

21. AHO: Protocolos de Bertomeu Roig, 1666; testamento de D. Gaspar Rocamora García de Lassa, en 26 y 27 de agosto de 1666

22. ACO: Protocolos de Ginés Martinez, 1636-39; Inventario de bienes realizado por Dil María García de Lassa tras el fallecimiento de su marido, D. Jerónimo Rocamora y Thomás, en 7 de noviembre de 1639 ; AHO: Protocolos de Juan Liñán, 1644-45; ff. 796-861v.: inventario de bienes realizado por D. Gaspar Rocamora García de Lassa tras el fallecmiento de su madre, Da María García de Lassa, en 1 de septiembre de 1645 . Vid. CUADRO I. 
19 las fincas de regadío, con una extensión aproximada de 3.408 tahúllas de huerta, y alcanzan la decena las de secano, con una amplitud indeterminada pero no muy alejada de las 10.000 tahúllas, mientras que, de las 2.000 de almarjales, no debían ser pocas las que estaban por entonces en cultivo ${ }^{23}$. En consecuencia, puede afirmarse que, a grandes rasgos, este tipo de patrimonio agrario no señorial se había quintuplicado en el transcurso de apenas dos generaciones. Es por ello que, en su testamento de 1691, D. Juan llevara a cabo una considerable ampliación del vínculo de Rafal, incorporando en él la mayor parte de las nuevas fincas, para protegerlas frente a posibles coyunturas desfavorables ${ }^{24}$.

$\mathrm{Si}$, por otro lado, tomamos en consideración la situación existente a medio camino entre ambas fechas -según los inventarios de 1666/67-, se observa que la acumulación patrimonial es relativamente más acentuada en la huerta en vida de D. Gaspar-segundo tercio del Seiscientos-, mientras que la incorporación de las heredades de secano se producirá más adelante, mayoritariamente durante el último tercio de la centuria, ya en tiempos de D. Juan como titular del marquesado. En 1666/67, en efecto, las fincas de regadío sobrepasan ligeramente la docena, mientras que el total de tahúllas que comprenden asciende ya a 2.535. El secano, por el contrario, permanecerá prácticamente intacto en relación con la situación observada dos décadas atrás, pues solo cabe anotar, como ganancia patrimonial, la incorporación de algunas fincas anexas a la primitiva cañada de Salinas, que -según se afirma en 1666- fue comprando D. Gaspar a diferentes personas, hasta cumplimentar unas 2.000 tahúllas $^{25}$

Además, la información correspondiente a la etapa final aquí considerada, ya en pleno Setecientos, permite concluir que el grueso del patrimonio, sin llegar a mantenerse estable, apenas experimentó incrementos significativos durante el medio siglo siguiente a la muerte del tercer marqués, acaecida en 1691. Así, aunque el patrimonio mencionado en el testamento de la marquesa, en 1736, o el integrante de la dote correspondiente a la heredera, en 1743, comprendía, además del mayorazgo de Rafal -expresamente ampliado, como ya se ha dicho, en 1691-, una serie de bienes libres, la mayoría de éstos ya figuraban como tales -«parafernales y extradotales»- en esta última fecha, pues procedían de la herencia materna recayente en $\mathrm{D}^{\mathrm{a}}$ Jerónima. Como máximo, durante este intervalo (1691-1736) es probable que sólo se consiguiera incorporar una cañada de secano - la hacienda de Guilarte, anexa a las fincas de Salinas, con 700 thas - y otra de huerta -los Palacios de Cascante, con 193 tahúllas de regadío y un trozo de campo anexo. Ciertamente, también constituyen posible novedad la aparición

23. ACO: Protocolos de Andrés Ximenez, 1691, ff. 258 y ss. Vid. CUADRO IV.

24. AHN: Consejos, Leg. 22.315, $1^{\text {a }}$ pieza, ff. 139-153v.: copia del testamento de D. Juan Rocamora Garcia de Lassa, en 25 de marzo de 1691. Los bienes añadidos al vínculo de Rafal fueron los adquiridos por D. Gaspar y por él mismo; esto es, los que figuran en la relación de 1691 -CUADRO IV- pero estaban ausentes en la de 1639 -CUADRO I.

25. AHO: Protocolos de Bertomeu Roig, 1666; inventario realizado por D. Juan Rocamora García de Lassa, tras la muerte de su hermano, D. Gaspar, en $1,2,3,4,13,25$ y 27 de septiembre, 24 de octubre y 28 de noviembre de 1666 
de otras fincas menores en la huerta -4 parcelas, con un total de 138 tahúllas-. Pero, en sentido inverso, en 1736 no hay rastro, en cambio, de otras 7 propiedades de regadío, que en 1691 sumaban 144 tahúllas. Se trataba, en todos los casos, de pequeñas fincas no vinculadas cuya disponibilidad permitía a los marqueses atender posibles necesidades que fueran surgiendo ${ }^{26}$.

El ritmo de acumulación patrimonial, un tanto inconstante, no debió ser del todo ajeno a la incidencia de ciertos elementos relacionados con la coyuntura económica y política. Pero el análisis de otras circunstancias relativas a las formas de adquisición ponen también de manifiesto la virtualidad de algunas estrategias inversoras que recuerdan las practicadas por el primer marqués. Así, las dificultades de las décadas centrales del XVII propician la incorporación, en óptimas condiciones, de algunas fincas valiosas, justamente en el entorno de los señorios de Rafal y de la Puebla y, en ocasiones, aprovechando las redes comerciales y crediticias tejidas por los marqueses. Algunos ejemplos entresacados de los protocolos notariales muestran claramente estas estrategias:

Ya en 1647 D. Gaspar consiguió hacerse con la titularidad de un vasto patrimonio agrario limítrofe al término de Rafal, constituído por dos heredades que, en conjunto, abarcaban 900 tahúllas de huerta -según parece, hipotecadas por un particular y recayentes en el Real Patrimonio, administrado por el Dr Francesc Arques- por un precio de 6.700 libras. La forma de hacer efectiva tan cuantiosa suma incluía desde el pago al contado -sólo 700 libras-, al aplazado, en varias anualidades -4.500 libras-, pasando por la consignación de deudas censales a que era acreedor -las 1.500 restantes $^{27}$. Y unos años más tarde, en 1661, el mismo adquiría -en la huerta del Almoradí- una gran heredad de 680 tahúllas, próxima a la baronía de la Puebla, por un precio de 3.109 libras, 8 sueldos y 6 dineros, a la comunidad de regantes del Azud de Alfeitamí-que se la había adjudicado en proceso de ejecución contra un regante arruinado-, pero, en esta ocasión, sin tener que hacer efectiva ni una sola libra de moneda. Siguiendo al pie de la letra la táctica practicada por su padre cuatro décadas atrás, como dicha comunidad de regantes fuera, a su vez, deudora de muchas pensiones atrasadas de un censal de 5.200 libras que respondía al marqués, éste accedió a la propiedad de la finca «a compte de les pencions discursses de aquel censal...que lo dit assut y hereters regants de aquell li son deutors $\rangle^{28}$. Pues bien, cinco años más tarde, el mismo D. Gaspar compraba a

26. A las fuentes ya mencionadas, correspondientes a 1691 y 1736, hay que añadir otra relación casi completa, para 1743. AHO: Protocolos de Josep Martínez de Rodriguez, 1743; capítulos matrimoniales entre D. Antonio de Heredia y Bazán y Da Antonia María Rocamora de Heredia, en 27 de octubre de 1743.

27. AHO: Protocolos de Josep Burello, 1647, escritura de compraventa, de 29 de junio de 1647. De las dos heredades, denominadas «Casa Grande» y «Caseta Chica», es posible que solo una permaneciera definitivamente entre los bienes de los marqueses, siendo conocida como «Heredad de Arques», a la que en 1666 se asignaban 400 tahúllas. El Dr. Arques era a la sazón abogado fiscal y patrimonial y el precio de la transacción iba destinado a las arcas reales, sujetándose a unas condiciones un tanto complejas, que inclúán el usufructo vitalicio de una porción de la finca menor por parte del noble D. Tomás Maza de Lizana.

28. AHO: Protocolos de Bertomeu Roig, 1661, escritura de compraventa, de 5 de agosto de 1661 
un particular otras 170 tahúllas contiguas a la finca anterior, por 700 libras, con lo que conseguía redondear la operación de acumulación patrimonial en una zona en la que, precisamente, se hallaban ubicados otros dominios propios -como la baronía de la Puebla, y los mencionados almarjales de la Maxada Viexa. Y, lo que no deja de ser significativo, tampoco en este caso hubo entrega de moneda corriente, pues el pago se realizó, en su mayor parte, en el traspaso de un salitre, con todo el material anexo, que poseía el marqués, así como en el derecho a cobrar el arrendamiento del mismo que le debía el «salitrer» y en 4 deudas a que era acreedor ${ }^{29}$.

Que los apuros ajenos podían ofrecer buenas oportunidades para hacerse con parcelas a buen precio era algo demasiado común; y así debió ocurrir en 1669 cuando D. Juan adquirió a una viuda endeudada la propiedad de dos cañadas de secano, de 100 tahúllas cada una, contiguas a las que el mismo poseía en el campo de las Salinas, por 59 '5 libras, subrogándose en los dos censales de 37'5 libras de propiedad que recaían sobre aquéllas y abonando el resto en efectivo ${ }^{30}$.

La preferencia por fincas contiguas a tierras propias, y especialmente al término de Rafal, quedaría de manifiesto en otras múltiples ocasiones: así, en 1670, cuando D. Juan compró 13 tahúllas, por 78 libras, tras haber obtenido por permuta otras 23 anexas, que formaban parte de la misma unidad de explotación ${ }^{31}$. Lindantes a tierras propias, en las inmediaciones de Rafal, estaban también las 25 tahúllas adquiridas al convento de la Cartuja de Viaceli en 1666, por 225 libras $^{32}$. Y una excepción a esta tendencia, que quizá guarde relación con posibles vinculaciones personales derivadas de la dependencia señorial, es el caso de la compra realizada por D. Jaime Rosell a un «llaurador» de su señorío de Benejúzar de una cañada de 100 tahúllas de secano ubicadas en el campo de Almoradi, pero cercano a sus fincas de las Salinas, por 50 libras $^{33}$.

Mas no siempre ha sido posible conocer el procedimiento seguido para hacerse con la titularidad de otras grandes heredades. Así ocurre, en el intervalo comprendido entre 1666 y 1691 , con la heredad de les Añores, de 200 tahúllas de huerta -junto a la frontera con Murcia-, posiblemente resultante de una ampliación de la finca de 65

29. AHO: Protocolos de Bertomeu Roig, 1666, escritura de compraventa, de 28 de febrero de 1666 . El valor del salitre, con la caldera, coladores, porchada, solar y tierra anexa, hasta 5 tahúllas de huerta, se estimó en 580 libras, de las que había que deducir un censal de 100 libras que se respondía al Hospital del Corpus de Orihuela; la deuda del «salitrer» ascendía a 40 libras, por media anualidad del precio de arrendamiento; a todo ello se añadían dos obligaciones por valor de 59 y 46 libras, respectivamente, y otras dos deudas, de 50 y 25 libras.

30. AHO: Protocolos de Bertomeu Roig, 1669; escritura de compraventa de 3 de enero de 1669.

31. AHO: Protocolos de Bertomeu Roig, 1670; en primera escritura, de 28 de febrero de 1670, D. Juan Rocamora permutó con Ginés Palomares y Mariana Alberola, conyuges, 23 tahúllas de tierra huerta que poséa en la partida de la arroba honda de la acequia de Escorratell, por otras tantas, en tres trozos, parte de una finca de 36 tahúllas, lindantes a tierras propias, anexas al término de Rafal. En escritura distinta, el mismo dia, D. Juan adquiría a los mismos las 13 restantes - hasta completar las 36-, por 78 libras.

32. AHO: Protocolos de Bertomeu Roig, 1666; escritura de compraventa, de 26 de enero de 1666.

33. AHO: Protocolos de Josep Martínez de Rodriguez, 1696; escritura de compraventa de 26 de marzo de 1696. 
tahúllas ya inventariada en ese pago en 1639; y con otra más extensa, de 600 tahúllas, ubicada en el pago de Guardalacapa, próxima a Rafal, posteriormente conocida como heredad de $\mathrm{D}^{\mathrm{a}}$ Inés.

Algo mejor conocidas resultan las incorporaciones patrimoniales realizadas en determinados parajes del extenso campo oriolano que, en las décadas finales del Seiscientos, estaban siendo objeto de un creciente esfuerzo roturador. A partir de un núcleo originario ya poseído en tiempos del primer marqués en el campo de las Salinas, mediante adquisiciones sucesivas los marqueses fueron ampliando sus dominios. Así, en referencia expresa a la cañada de las Salinas, que ya figuraba entre los bienes de D. Jerónimo a principios del XVII, se afirmaba en 1666 que su extensión alcanzaba ya las 2.000 tahúllas y que se había ido formando por compras a diferentes personas ${ }^{34}$. Y, en efecto, sólo durante el año anterior D. Gaspar había realizado cinco adquisiciones de cañadas a otros tantos particulares, que sumaban una extensión total de 1.400 tahúllas de secano, por un importe total de 377'2 libras, a las que había que añadir otras dos compras anteriores, que habrían aportado otras 400 tahúllas más ${ }^{35}$. De este modo, mediante la reagrupación parcelaria, se fueron configurando dos grandes unidades de explotación en un paraje tradicionalmente despoblado y poco atractivo debido a su lejanía de la ciudad y a su indefensión ante la frecuente amenaza pirática, pero que, en las décadas siguientes, iba a ser objeto de frecuentes asentamientos ${ }^{36}$. Las perspectivas de revitalizacón agraria de la zona no debieron ser ajenas al interés de los marqueses por incrementar allí su presencia patrimonial, de modo que también D. Juan continuó añadiendo nuevas cañadas, como revelan sendas adquisiciones de 100 tahúllas cada una, contiguas a las anteriores, realizadas en $1669^{37}$. Ya en 1666 hay constancia de dos unidades de explotación en la zona, que responden a la denominación de Casa Grande y Casa Chica del campo de las Salinas ${ }^{38}$, y que, una década más tarde, son mencionadas como «Cañada Grande»y «Cañada del Peinado» ${ }^{39}$. En 1691 las dos fincas contiguas

34. AHO: Protocolos de Bertomeu Roig, 1666; inventario realizado por D. Juan Rocamora García de Lassa, tras la muerte de su hermano, D. Gaspar, en 1,2,3, 4, 13, 25 y 27 de septiembre, 24 de octubre y 28 de noviembre de 1666

35. AHO: Protocolos de Bertomeu Roig, 1665; escrituras de compra-venta de 16 de enero (700 tahúllas por 160 libras), 3 de marzo (200 tahúllas por 66'3 libras), 13 de abril (200 tahúllas por 60 libras), 16 de julio (200 tahúllas por 66 libras) y 17 de octubre de 1665 (100 tahúllas por 25 libras). En los lindes de estas cañadas se mencionan otras dos distintas, también propias del Marqués, con los nombres respectivos de sus anteriores propietarios.

36. Sobre esta cuestión, vid. Millán y Garcia-varela, Jesús: Rentistas..., p. 86; Bernabé Gll, David y RICO JIMÉNEZ, Juan: «Dificultades de una repoblación de frontera: el monasterio de San Ginés y el litoral oriolano (siglos XV-XVII)», en La población valenciana. Pasado, presente, futuro, Instituto de Cultura Juan Gil-Albert, Alicante, 1998, vol. I, pp. 367-384.

37. AHO: Protocolos de Bertomeu Roig, 1669; escrituras de compra-venta, de 2 de enero de 1669.

38. AHO: Protocolos de Bertomeu Roig, 1666; inventario realizado por D. Juan Rocanora García de Lassa, tras la muerte de su hermano, D. Gaspar, en 1,2,3, 4, 13, 25 y 27 de septiembre, 24 de octubre y 28 de noviembre de 1666 .

39. AHN: Consejos, Leg. 22.004, expte. 9. 
ubicadas en dicho campo son nombradas como «Cañada de las Salinas» y «Cañada de las Sahurdas», pero, tras la recuperación de los bienes confiscados durante la guerra de Sucesión, ascienden a cuatro las unidades de explotación poseídas en dicho paraje, con una extensión total superior a las 3.000 tahúllas: Casa Grande, Casa Alta, Las Sahurdas y Guilarte ${ }^{40}$.

La presencia de los marqueses en el campo oriolano aun abarcaría otras dos grandes fincas, que figuran por vez primera en el inventario de 1691, y cuyas vías de integración en el patrimonio familiar nos resultan desconocidas. Se trata de la «Cova Forte», no muy alejada de las Salinas, en el campo de San Ginés, de unas 900 tahúllas de secano; y, en el campo de la Matanza, al otro extremo del término municipal oriolano, ya en el interior, de una heredad de secano de unas 3.000 tahúllas ${ }^{4 !}$.

Las posesiones que pasaron a engrosar el patrimonio de los marqueses no siempre procedían de compraventas. Quizá algunas de las heredades que se acaban de mencionar -expresamente incluías en la ampliación del vínculo de Rafal, llevada a cabo por D. Juan en 1691- habían recaído en sus dominios en virtud de derechos hereditarios provenientes de ramas colaterales sin sucesión directa. $Y$, aunque de origen algo distinto, el incremento patrimonial del que se benefició como consorte el propio D. Juan -y que luego pasaría a su hija, $D^{a}$ Jerónima, cuando tomara posesión en 1691-, tampoco conllevó desembolso alguno en efectivo. Las valiosas fincas que ésta añadió a la herencia paterna, catalogadas como bienes «parafernales y extradotales» procedían del patrimonio materno y consistían en una heredad de 190 tahúlias -entre huerta y campo-, denominada la Media Legua, dos fincas de secano de 70 y 80 tahúllas, respectivamente, $y$ otras tres grandes heredades, denominadas Casa Grande y Caseta de Cascante, de 1.010 tahúllas entre las dos, en su mayor parte irrigadas; y Dehesa y Torre de Cascante, de 1.000 tahúllas de secano, pero que incluía también «lo dret de herbaje, dehesa y señorio que tots los anys acostume a vendre ab privilegis particulars concedits per los señors Reys Catolichs $\rangle^{42}$. Al carecer de herederos directos, $\mathrm{D}^{\mathrm{a}}$ Jerónima no habría de mostrar luego demasiado interés en mantener estas fincas en la linea de Rafal; pero su condición de integrantes de un fideicomiso instituído en 1665 por su abuelo materno, D. Pedro Cascante y Ruiz ${ }^{43}$, facilitó su reincorporación en dicha linea, tras largo pleito

40. ACO: Protocolos de Andrés Ximenez, 1691, ff. 258 y CUADRO VII, respectivamente.

41. Aparecen por vez primera en la relación contenida en el testamento de D. Juan Rocamora Garcia de Lassa, en 25 de marzo de 1691. (AHN: Consejos, Leg. 22.315, 1" pieza, ff. 139-153v.)

42. ACO: Protocolos de Andrés Ximenez, 1691, ff, 258 y ss. Vid. CUADRO IV. Sobre la caracterización de las dehesas como formas de dominio cuasi señorial, vid. BERNABÉ GIL, David: «Una coexistencia conflictiva: municipios realengos y señoríos de su contribución general en la Valencia foral", Revista de Historia Moderna, $1^{\circ} 12,1993$, pp. 43 y ss.

43. AHO: Protocolos de Bertomeu Roig, 1665; testamento de D. Pedro Cascante y Ruiz, el 10 de abril de 1665, y codicilo el 13 de abril del mismo año; asímismo, cartas matrimoniales entre D. Pedro Cascante y Di Luisa Cascante, de 12 de enero del mismo año 
del sucesor del marquesado contra el usufructuario designado por disposición testamentaria de aquélla, mediante sentencia de la Audiencia de Valencia, en $1740^{44}$.

Con posterioridad a 1691 no parece que se produjeran incorporaciones de relieve, pues aunque unas décadas más tarde la documentación registra algunas heredades ignoradas en un listado completo correspondiente a aquel año, parecen tratarse de partes individualizadas de grandes fincas ya poseídas. Así ocurre -al menos a partir de 1729- con la mayor parte de las ya mencionadas haciendas del campo de las Salinas ${ }^{45}$. Tampoco la denominada Casa Nueva de Rafal, en el término del marquesado, con unas 400 tahúllas de huerta, ni la Cañada de Cascante, con 150 de secano, constituyen enteramente novedades patrimoniales cuando son nombradas en el siglo XVIII, pues la primera alude a la parte del señorío que no llegó a establecerse a los vasallos, y la segunda procede de la ampliación de la cañada del Cabezo de Hurchillo, originariamente de 70 tahúllas, a las que luego se añadirían «las lomas vertientes». Esta estrategia, consistente en la ampliación territorial a través de tierras anexas - a veces baldías o mostrencas-, debió practicarse también en las haciendas ubicadas en el campo de las Salinas, en la de la Matanza y en la cañada de la Foia del Cabeco. No ha de sorprender, por tanto, que con el paso del tiempo los nuevos marqueses les atribuyan unas dimensiones mayores que las que figuran en épocas anteriores ${ }^{46}$. Y esta tendencia llegó a afectar incluso a las fincas de la huerta, aunque en estos casos no cabe descartar el impacto de posibles errores de apreciación en su medición, pues también se manifiesta en sentido contrario ${ }^{47}$.

44. AHO: Protocolos de Josep Martínez de Rodriguez, 1740; poder otorgado por D. Jerónimo Rocamora y Cascante, el 2 de mayo de 1740

45. El desconocimiento de un hipotético imventario de bienes realizado tras el fallecimiento de $D^{4}$ Jerónima, en 1736, puede suplirse parcialmente con la relación de bienes aportados al matrimonio por la heredera posterior del título de Rafal, $D^{a}$ Antonia Rocamora de Heredia, en 1743, en sus apartados de «Mayorazgo de Rocamora y Marquesado de Rafal», «Mayorazgo de Cascante»e incluso «Bienes libres»; aunque no es seguro que esta fuente recoja la totalidad de las posesiones (AHO: Protocolos de Josep Martinez de Rodriguez, 1743; ff. 205-225v, cartas matrimoniales entre D. Antonio de Heredia y Bazán y Da Antonia Rocamora y Heredia, en 27 de octubre de 1743. Vid. CUADRO VI

46. Así, a la heredad la Casa Grande de Salinas se le asignan 800 tahúllas en 1729 y 900 en 1734,1741 y 1743; a la Casa Alta o del Peinado, contigua a la anterior, 400 tahúllas en 1729,800 en 1741 y 700 en 1743; a la de Guilarte, también anexa, 500 tahúllas en 1729 y 700 en 1741 y 1743 ; a la de las Sahurdas, en el mismo paraje, 800 tahúllas en 1729,850 en 1734 y 1.000 en 1743; a la heredad de la Matanza, 3.000 tahúllas en 1734 y 4.000 en 1743; a la cañada La Foia del Cabeco, 70 tahúllas en 1665 y 100 en 1729, 1734 y 1743. Los datos de 1729 proceden de AHO: Protocolos de Bernabé Aniorte, 1726, ff. $64-70 \mathrm{v}, 162-175 \mathrm{v}, 178 \mathrm{v}-200 \mathrm{v}, 297-218 \mathrm{v}$; escrituras de arrendamiento de 4 y 26 de enero, 20, 21, 22 y 23 de mayo de 1726. Los de 1734, de AHO: Protocolos de Bautista Aleman, 1734, ff. 100-101, 126$127 \mathrm{v}, 132-136,155-156 \mathrm{v}, 160-161 \mathrm{v}, 170-17 \mathrm{lv}, 182-183 \mathrm{v}, 188-189 \mathrm{v}, 195-198 \mathrm{v}, 200-205 \mathrm{v}$, escrituras de arrendamiento suscritas durante los meses de septiembre, octubre y noviembre de 1734. Los de 1741, de AHO: Protocolos de Josep Martinez de Rodriguez, 1741; ff. 1-141v, escrituras de arrendamiento suscritas entre el 2 de enero y el 3 de febrero de 1741. Los datos de 1743 proceden de AHO: Protocolos de Josep Martínez de Rodriguez, 1743; ff. 205-225v, cartas matrimoniales entre D. Antonio de Heredia y Bazán y $D^{a}$ Antonia Rocamora y Heredia, en 27 de octubre de 1743

47. Así, la finca formada con la heredad de D. Felipe Ocaña y otras 170 contiguas figura con 770 tahúllas en 1666,1667 y 1691,800 en 1725 y 1729,816 en 1735,822 en 1741 y 1743 ; la heredad de Saavedra, 


\section{CUADRO VI}

Relación parcial de los bienes aportados al matrimonio por $\mathrm{D}^{\mathrm{a}}$ Antonia Rocamora de Heredia (1743)

Mayorazgo de Rocamora y Marquesado de Rafal Marquesado de Rafal

Heredad de Arques, de 490 tahúllas huerta

Heredad de Saavedra, de 300 tahúllas huerta

Heredad Casa Nueva de Rafal, de 440 tahúllas huerta

Heredad de Tell, de 330 tahúllas huerta

Heredad La Matanza, de 4.000 tahúllas secano

Baronía de La Puebla, de 2.010 tahúllas huerta

Almarjales contiguos, en litigio con las PP.FF, con 4.600 tahúllas

Heredad la Era Alta, de 130 tahúllas huerta

Heredad de D. Felipe Ocaña, de 722 tahúllas huerta

Heredad de Da Ines en Guardalacapa, de 600 tahúllas huerta

Heredad Las Añoras, de 140 tahúllas huerta

Huerto cercado Las Palmeras

Heredad Casa Grande de Salinas, de 900 tahúllas secano

Heredad Casa Alta del Peinado, en Salinas, de 700 tahúllas secano

Heredad de Guilarte, en Salinas, de 700 tahúllas secano

Heredad de Las Sahurdas, en Salinas, de 800 tahúllas secano

Heredad La Cueva Fuerte, en S. Ginés, de 1.000 tahúllas secano

Huerto de 11 tahúllas de moreras, riego de la Acequia Los Huertos

Casa principal en Orihuela

Casa-horno en Orihuela

Casa-taberna en Orihuela

3 casas en Orihuela

3 solares de casas en Orihuela

Casa en Almoradí

Censo de 7.500 libras sobre la ciudad de Orihuela

Mayorazgo de Cascante

Casa principal en Orihuela

Heredades Casa Grande y Caseta de Cascante, de 1.050 tahúllas huerta

Heredad Torre y dehesa de Cascante, de 1.000 tahúllas secano y coto

Heredad Palacios de Cascante, de 193 tahúllas huerta y trozo de secano

Censo de 1.500 libras

Bienes libres

4 parcelas, de 138 tahúllas huerta

con 200 tahúllas en 1666, 283 en 1726, 263 en 1729, 260 en 1734, 300 en 1743. En sentido inverso, la heredad de las Añoras figura con 200 tahúllas en 1691, 140 en 1729, 180 en 1734, 140 en 1741 y 1743. La relación de fuentes, para el siglo XVIII, en nota anterior; a las que cabe añadir, para 1735, Protocolos de Bautista Aleman, 1735, ff. 51-52, escritura de arrendamiento de 7 de febrero. Para el siglo XVII, vid supra, notas 38 y 39 . 
Casa en Orihuela

Otros

Cañada de Cascante

70 tahúllas huerta en Correntías

Fuente: AHO: Protocolos de Protocolos de Josep Martinez de Rodriguez, 1743; ff. 205-225v, cartas matrimoniales, de 27 de octubre de 1743 .

Finalmente, en lo que se refiere a las estrategias de acumulación patrimonial en el realengo, cabe añadir que algunas parcelas de menor tamaño que las mencionadas, aunque generalmente de elevado valor por su condición de huerta, fueron objeto de compras y ventas con alguna frecuencia, con un saldo final ligeramente favorable. $Y$ así como las grandes unidades de explotación acabaron siendo objeto de vinculación, engrosando el patrimonio de forma irreversible, las de dimensiones más reducidas permanecieron por lo general como bienes de libre disposición. De este modo, quedaban a merced de las posibles necesidades o usos alternativos que pudieran surgir, tanto para permutarlas por otras de mayor interés estratégico -especialmente, en el entorno de los núcleos señoriales--, como para gratificar servicios prestados, o incluso para hacer frente a derechos hereditarios colaterales.

\section{FINCAS URBANAS}

Junto a esta importante acumulación patrimonial de fincas rústicas, también las propiedades urbanas experimentaron un crecimiento considerable, especialmente concentrado durante el periodo comprendido entre 1666 y 1691. Mención aparte de las casas existentes en las grandes heredades, de las dos únicas casas de habitación poseídas por D. Gaspar en 1645, ubicadas en la ciudad de Orihuela y en la universidad de Almoradí, a las que cabe añadir dos más en 1666, se pasa a una decena a la altura de 1691. Las nuevas adquisiciones, cuyo origen y modalidad de acceso se desconoce, se ubicaban siempre en la ciudad del Segura, y su concentración durante el periodo señalado coincide con una relativa paralización de las inversiones en la huerta, aunque no en el secano. Posteriormente, esta faceta inversora quedaría un tanto desatendida, aunque se hallaba parcialmente protegida por la ampliación del vínculo realizada por D. Juan en 1691. Así, en la relación de bienes aportados al matrimonio por la marquesa en 1743 figuran incluso menos casas que medio siglo atrás, al haber quedado algunas reducidas a solares; y aunque hay constancia de alguna nueva adquisición durante ese intervalo temporal, también la hay de alguna venta producida ${ }^{48}$.

Fue también en vida de D. Juan cuando pasaron a engrosar el patrimonio otros dos inmuebles urbanos ubicados en la ciudad de Orihuela, consistentes en una casa-horno y una casa-tienda -comprendidos en los bienes agregados al vínculo en 1691-, mientras que el origen de un huerto cercado con palmeras, con su casa «per a habitacio

48. Ejemplo de adquisición, en AHO: Protocolos de Josep Martinez de Rodriguez, 1738; ff. 97-100v, escritura de 31 de enerao de 1738; ejemplo de venta, en AHO: Protocolos de Bautista Alemán, 1735, escritura de 27 de enero de 1735 . 
del hortola», se remonta a tiempos del primer marqués, quien lo incluyó en el vínculo instituído en 1638. En consecuencia, también la inversión inmobiliaria en el marco urbano formó parte de la estrategia patrimonial de los marqueses durante el último tercio del Seiscientos, para estabilizarse posteriormente, al igual que ocurriera con el patrimonio rústico. La Guerra de Sucesión y sus devastadoras consecuencias para una familia que apostó fuerte por el austracismo demoraron durante décadas la capacidad de recuperación de los titulares del marquesado.

\section{LA CABAÑA GANADERA}

Pero donde el nefasto impacto patrimonial de la contienda sucesoria quedó expresado de forma más palmaria fue, posiblemente, en la cabaña ganadera. La crianza de ganado mayor se había erigido tradicionalmente -desde principios del Seiscientos-en un negocio que debía proporcionar pingües beneficios a los Rocamora, toda vez que les permitía abastecer de ganado de diverso tipo, destinado a variados menesteres -tiro, carga, corridas, alimento-, a varias comarcas del sur valenciano y de la vecina Murcia, a un coste no demasiado elevado. La gratuidad del alimento necesario para su mantenimiento y reproducción resultaba esencial para alcanzar la necesaria rentabilidad, y a tal fin los sucesivos marqueses orientaron algunas de sus estrategias agrarias. Si ya D. Jerónimo destacó en esta faceta, marcando las directrices a seguir, mediante la anexión de extensas zonas de majadas y pastos comunitarios, la incorporación patrimonial de fincas contiguas a los mismos, o el simple uso de zonas abiertas al libre apacentamiento de su extensa cabaña, sus sucesores no descuidaron la prosecución de prácticas similares. El resultado habría de ser, por tanto, una creciente y constante ampliación del número de cabezas de ganado mayor -yeguar y vacuno, fundamentalmente-, al menos hasta finales del siglo XVII.

Las poco más de 300 cabezas de vacuno y las 160 yeguas -mención aparte del ganado de tiro y de carga existente en las heredades y señoríos- que heredó D. Gaspar, se habían transformado ya en cerca de 700 y en algo más de un centenar, respectivamente, en el momento de su muerte ${ }^{49}$. Quedaba así sobradamente cumplida la postrera voluntad de su madre, la marquesa viuda, quien había prohibido en su último testamento que el heredero pudiese echar mano de este ganado mayor para atender los derechos hereditarios de sus hermanos, a excepción de las crías o «fruits de les dites egues y vaques $\rangle^{50}$. De hecho, cuando en 1649 se hicieron efectivas las 6.000 libras de la dote de $\mathrm{D}^{\mathrm{a}}$ Catalina, por parte de su hermano D. Gaspar, más de la mitad de aquélla se entregó en crías de ganado mayor ${ }^{51}$.

49. AHO: Protocolos de Bertomeu Roig, 1666; inventario realizado por D. Juan Rocamora Garcia de Lassa, tras la muerte de su hermano, D. Gaspar, en 1,2,3,4,13,25 y 27 de septiembre, 24 de octubre y 28 de noviembre de 1666

50. AHO: Protocolos de Juan Liñan, 1644-45; codicilo de 13 y 17 de mayo de 1645.

51. AHO: Protocolos de Bertomeu Roig, 1649; escrituras de donación y cartas matrimoniales, de 3 de mayo de 1649 . 
Durante estas dos décadas y media fueron innumerables, en cambio, las ventas de ganado mayor que registran los protocolos notariales, generalmente a labradores, pero también a consistorios, de un extenso radio territorial. $\mathrm{Y}$ así continuó sucediendo durante el último tercio de la centuria, pues también $\mathrm{D}$. Juan consiguió imprimir un notable impulso a la empresa ganadera, a pesar de los problemas planteados por la viuda de su predecesor -quien, tras reclamar la cuarta parte de la cabaña, al parecer descuidó bastante su conservación ${ }^{52}$; de modo que en la herencia recibida por su hija, $\mathrm{D}^{\mathrm{a}}$ Jerónima, en 1691, se anotaban ya un total de 920 cabezas de vacuno y de 248 de yeguar, caballar y mular, con un valor conjunto estimado de 22.000 libras $^{53}$.

Una pormenorizada relación de la situación en que se hallaba la cabaña ganadera, para 1677, permite comprobar, en efecto, el intenso aprovechamiento que se hacía de las majadas y humedales propios de la ciudad de Orihuela, pero colindantes a tierras propias de los marqueses; lo que denota la finalidad de, al menos, una parte significativa de las estrategias de acumulación patrimonial relativas a la tierra que venían desplegándose desde principios de la centuria. La extensa y variada cabaña ganadera se hallaba distribuida aquel año en cinco hatos, cada uno de ellos al frente de un mayoral, ubicados en otras tantas zonas: en la denominada Majada Vieja, propiedad de los marqueses anexa a la baronía de La Puebla, se hallaban un total de 76 cabezas de caballar, entre yeguas, potros, mulas y asnos; en otros tres parajes de almarjales, contiguos a la anterior, pero integrantes de los comunales administrados por la ciudad de Orihuela, y denominados respectivamente «lo asarp nou», «lo cap del escorredor» y «frent a Matarredona», se encontraba el grueso del ganado vacuno, con 113, 136 y 200 cabezas, a las que se sumaban 8,6 y 10 asnos. Finalmente, en el almarjal municipal denominado «de la Puerta de Murcia», en el otro extremo del término oriolano, junto a la heredad de las Añoras - propia del marqués-apacentaban 50 yeguas y 9 asnos; todo ello, sin contar los animales de labranza que permanecían en las heredades ${ }^{54}$.

El aprovechamiento productivo de la crianza ganadera se realizaba esencialmente -además de la probable comercialización directa de la leche-- a través de la venta de ejemplares a labradores, para carga, tiro y labores agrícolas, generalmente mediante pago aplazado y la correspondiente firma de obligación ante notario; así como para corridas de toros a instituciones municipales, y abastecedores de carnicerías municipales. Pero, según se declaraba en 1677 , también era frecuente su alquiler a labradores

52. AHN: Consejos, Leg. 22.004, Expte. $n^{\circ} 9$, ff. 372-377

53. ACO: Protocolos de Andrés Ximenez, 1691, ff. 258 y ss. Vid. CUADRO IV. El desglose es el siguiente: 120 «bous de llauro de les heretats», valorados en 3.500 libras; 500 «vaques de ferro», valoradas en 5.000 libras; 300 «toros, cabestros y novillos», valorados en 6.000 libras; 48 mulas, valoradas en 3.120 libras; 120 «caps de yegues de ferro», valoradas en 3.600 libras; y 80 «asnes y someres», valorados en 800 libras.

54. AHN: Consejos, Leg. 22.004, Expte. $\mathrm{n}^{\circ} 9$, ff. 12-23. Sobre el uso de estos almarjales y las prácticas de los ganaderos para mantener el humedal, vid. BERNABÉ GIL, David: «Insalubridad y bonificaciones de almarjales en el Bajo Segura antes de las Pias Fundaciones de Belluga», Revista de Historia Moderna, $\mathrm{n}^{\circ} 17,1998-99$, pp. 53-57 
que no podían permitirse el desembolso de su precio de compra, para faenas agrarias, como era el caso de las yeguas para la trilla ${ }^{55}$.

Frente a esta numerosa y valiosa cabaña, la cria de ganado menor parece perder protagonismo después de los dias de D. Jerónimo, pues aunque resulta abundante en el inventario realizado tras su fallecimiento, en 1639, con un total de 1.695 cabezas de ovino y 163 de porcino, en lo sucesivo desaparece toda mención a su existencia. Posiblemente, la mayor desproporción entre el beneficio y los costes que requería su mantenimiento, dadas las insuficiencias que presentaba el término oriolano en pastizales libres y gratuitos, contribuyó al desinterés por su mantenimiento. $Y$ al ser más efímera su existencia y rápido su consumo, los marqueses pudieron desprenderse del mismo con bastante facilidad. No obstante esta tendencia, todavía en el inventario de 1666 puede hallarse una partida de 353 libras «del ganado que se ha desfet en las carniceries de la ciutat» ${ }^{56}$.

Más difícil de explicar resulta, por otro lado, la desaparición a lo largo del siglo XVIII de toda mención al otrora abundante ganado vacuno y caballar. Unicamente los desastres provocados por la Guerra de Sucesión, quizás las perentorias necesidades de aprovisionamiento de carne y cabalgaduras, y el destacado protagonismo del marqués en el bando austracista, que determinó su prolongada y forzada ausencia del entorno oriolano y la confiscación de sus bienes, podrían justificar la definitiva quiebra de este patrimonio semoviente ${ }^{57}$. Así, tras la muerte de D. Jaime Rossell, varios testigos aludían a las irreparables pérdidas experimentadas en la zona de los almarjales de la Majada Vieja y aledaños «con las turbulencias y contratiempos de las guerras, y por la ausencia de los Marqueses, junto con la gran falta de Haberíos y Cavallerías, por habérselas llevado las tropas $)^{58}$. Por otro lado, ni en el testamento de 1736 , ni en las cartas dotales de 1743, referentes a los titulares de Rafal, donde se ofrecen relaciones suficientemente detalladas de los distintos componentes del patrimonio, libre y vinculado, mueble e inmueble, se recoge la más pequeña referencia a cabaña ganadera alguna, al

55. AHN: Consejos, Leg. 22.004, Expte. nº 9, ff. 372 y ss.

56. AHO: Protocolos de Bertomeu Roig, 1666; inventario realizado por D. Juan Rocamora García de Lassa, tras la muerte de su hermano, D. Gaspar, en $1,2,3,4,13,25$ y 27 de septiembre, 24 de octubre y 28 de noviembre de 1666 .

57. Sobre su participación en la Guerra de Sucesión, encabezando el bando austracista en el sur valenciano, vid. Pardo y manuel de villena, Alfonso: El Marqués de Rafal....; Pradells Nadal, Jesús: Del foralismo al centralismo. Alicante 1700-1725, Universidad de Alicante-Caja de Ahorros Provincial de Alicante, Alicante, 1984, pp. 55-69. Rosell acompañó al Archiduque a Barcelona, luego pasó a Mallorca, donde ejerció como Virrey; luego se exilió en Viena, donde formó parte del Consejo de Estado, y posteriormente lo encontramos en la ciudad de Milán. Tras la Paz de Viena residió un corto periodo en la ciudad de Valencia, hasta su regreso a Orihuela y Benejúzar para recobrar el control directo sobre sus posesiones. Hay constancia de su residencia en Milán el dia 3 de junio de 1725, en que otorgó poderes en favor del deán de la catedral de Orihuela D. Francisco Rocamora y Cascante (AHO: Protocolos de Bernabé Aniorte, 1726; f.. 4).

58. AMM: Colección Alegría; Caja 39, № 287: Memorial ajustado... del pleito seguido por los Marqueses de Rafal...con los administradores de las Reales Pias Fundaciones..., f. 45v. 
tiempo que los protocolos notariales persisten en su absoluto mutismo en torno a escrituras referentes a ventas de ganado, que habian sido tan frecuentes en el siglo XVII.

\section{CRÉDITOS}

Evolución algo distinta a la anterior experimentó, en cambio, el activo crediticio que había conseguido acumular el primer marqués de Rafal. Integrada fundamentalmente por censales cargados sobre instituciones con las que mantenía, además, estrechos lazos de diverso orden, la deuda a largo plazo dejó de ser un objetivo a tener en cuenta en las estrategias inversoras de sus sucesores. Y ello, a pesar de que, en uno de sus testamentos, el artífice del marquesado había expresado su deseo de ser imitado por el hereu ${ }^{59}$. Los continuadores en el título de Rafal, sin embargo, debieron valorar más otras fórmulas alternativas de colocar sus capitales, especialmente a la vista de las dificultades para percibir las cantidades adeudadas en los plazos previstos y, en consecuencia, de los desagradables pleitos que debían forzar para poder hacer efectivos sus derechos como acreedores. Con todo, al tratarse de créditos con amortización del capital a plazo indefinido, a voluntad del deudor, la tendencia general obraba a favor de su perpetuación

Por un lado, el censal que recaía sobre la ciudad de Orihuela, tras varias concordias para la liquidación de atrasos, quedó fijado definitivamente en 1641 en un principal de 7.500 libras, que respondía 375 anuales de pensión; y así permaneció durante todo el periodo aquí considerado, sin que su percepción, al parecer, llegara a originar nuevos pleitos. No faltaron ocasiones, ciertamente, en que el consistorio oriolano dejó de satisfacer temporalmente las pensiones anuales a sus acreedores, entre los que se encontraban los marqueses. Determinadas calamidades que generaban gstos inexcusables a la hacienda municipal, al tiempo que una brusca caída de los ingresos fiscales, como las epidemias de peste de 1648 y 1678 , forzaron negociaciones con los acreedores para hacer frente a la situación, que, sin embargo, no afectaron a medio y largo plazo a las relaciones crediticias con la Casa de Rafal ${ }^{60}$.

Pero algo distintas y más complejas fueron las relaciones mantenidas con la comunidad de regantes del Azud de Alfeitamí, cuya deuda consolidada en favor del creador del marquesado ascendía, en el momento de su fallecimiento -en 1639-, a 5.074 libras de capital censal, con pensión anual de 253'7 libras. Más que su condición de grandes hacendados en la huerta administrada por esta comunidad de regantes, fue la imprecisión de la extensión de los dominios del marqués sujetos a derramas de riego, lo que se convirtió en frecuente fuente de problemas, que acabaron afectando a la percepción de las deudas contraídas. Al estar buena parte de aquellos terrenos justo en la zona de transición al humedal y, en consecuencia, sujetos a continuos vaivenes que dificultaban una medición definitiva, las discrepancias acerca de las obligaciones tributarias -esta-

59. BERNABE GIL, David: «La formación...», p. 20 y ss.

60. BernabÉ GIL, David: Hacienda y mercado urbano en la Orihuela foral moderna, Instituto de Estudios Juan Gil-Albert, Alicante, 1989, pp. 106-112. 
blecidas en función de la extensión de tierra poseída- derivaron asímismo en impagos de las derramas asignadas. Al negarse a contribuir los marqueses por la cantidad de tierra que les atribuían los padrones confeccionados al efecto, la comunidad de regantes se consideraba legitimada para dejar de satisfacerle las pensiones del censal. O viceversa. No escasearon, por tanto, los pleitos entre ambas partes, con soluciones arbitrales o negociadas mediante concordias para liquidar atrasos y clarificar las obligaciones respectivas. Así, tras varios pleitos de los que se tiene noticia -en 1651, 1671 y 1676-, en 1694 se llegaba a acuerdo verbal para satisfacer temporalmente a la marquesa una pensión anual de 507 libras -el doble de la habitual-, al objeto de ir liquidando atrasos; y tres años más tarde, tras una detallada reconstrucción de las cuentas - a partir de 1653- se reconocía ya formalmente -mediante concordia escrita- a $\mathrm{D}^{\mathrm{a}}$ Jerónima como acreedora de un total de 12.925 libras y 11 sueldos ${ }^{61}$. En 1700, sin embargo, proseguían las discrepancias entre ambas partes ${ }^{62}$; mientras que en 1714 eran los administradores de los dominios secuestrados al marqués quienes hubieron de hacer frente a las denuncias presentadas por los regantes del azud de Alfeitami, ante el Consejo de Castilla, por impago de derramas ${ }^{63}$.

La tercera deuda de importante cuantía en favor de los marqueses, vigente al heredar el título D. Gaspar, se trataba de un cambio de 14.000 libras de capital, al cinco por ciento de interés, contraído por el Marqués de los Vélez. Aunque este tipo de empréstitos solían amortizarse a medio plazo, en 1666 no sólo persistía, sino que, conjuntamente con los intereses atrasados, ascendía a 17.000 o 18.000 libras, pues estaba pendiente de resolución judicial ${ }^{64}$. El hecho de que ya no figure en la relación de 1691 hace suponer que se habría liquidado en dicho intervalo de tiempo.

Junto a la perpetuación de estas antiguas deudas a plazo largo o indefinido, contraídas por instituciones en algunos casos, fueron pocas las que se añadieron, de naturaleza similar, en tiempos de los sucesores de D. Jerónimo. Solamente la estrecha vinculación mantenida por D. Gaspar con la ciudad de Murcia, donde residían sus suegros y, probablemente, él mismo durante algunos años, le llevaría a establecer algunas relaciones crediticias en dicho ámbito, pues tras su fallecimiento, en 1666, su heredero inventariaba un juro de 600 reales y un censo sin cuantía especificada que recaían sobre aquella ciudad ${ }^{65}$.

$\mathrm{Si}$, en general, los préstamos a largo y medio plazo no llegaron a alcanzar una gran consideración en las estrategias inversoras de los sucesores de D. Jerónimo, las obligaciones y otras fórmulas de reconocimiento de deuda a corto término también fueron

61. AJPAAA: Libro $N^{\prime \prime 3}$. Ma de determinacions y provisions fetes per los elets dels hereters regants del Azud de Alfaytani desde el any 1665 en avant, ff. 32, 41-42v, 51-53, 123-124, 164-184

62. Ibidem, ff. 330-334.

63. AHN: Consejos, Leg. 22.033

64. AHO: Protocolos de Bertomeu Roig, 1666; inventario realizado por D. Juan Rocamora García de Lassa, tras la muerte de su hermano, D. Gaspar, en 1,2, 3, 4, 13, 25 y 27 de septiembre, 24 de octubre y 28 de noviembre de 1666.

65. Ibidem. 
reduciendo paulatinamente su protagonismo; aunque en muchos casos eran resultado de transacciones a pago aplazado, que implicaban ventas de bienes propios, generalmente cabezas de ganado. Así, de las 502 obligaciones inventariadas en 1639, por un valor total de 33.034 libras, en 1644 quedaban solo 11.936 libras, repartidas entre 232 deudores. Ahora bien, el 80 por ciento de estas obligaciones no se remontaban a los tiempos del primer marqués, sino que habían sido contraídas durante los últimos cinco años. Tal situación es claro indicio, en primer lugar, de la persistencia de esta modalidad crediticia como fórmula transaccional -ante los previsibles problemas de liquidez de los compradores-, aunque ahora se practicara con menor profusión; en segundo término, de la pronta cancelación de la mayor parte de las antiguas obligaciones, algunas de las cuales habrían de permanecer, no obstante, incobrables ${ }^{60}$; finalmente, de su virtualidad como activo patrimonial con que hacer frente a derechos hereditarios de familiares: En 1648, por ejemplo, D. Gaspar hizo efectivas las 6.000 libras que estaba obligado a entregar a su hermana María, como dote matrimonial, en créditos de todo tipo ${ }^{67}$.

Y las tendencias apuntadas debieron de agudizarse en lo sucesivo, pues en 1666 el capital en obligaciones había descendido hasta la mitad, con solo 5.207 libras, repartidas entre 111 deudores, a las que cabía añadir 3.615 reales «en vales por cobrar en Castilla» y «lo que deben los pobladores de Rafal» ${ }^{68}$. Más aun, de forma incluso sorprendente, esta modalidad de activo financiero deja ya de ser mencionada en el inventario de 1691 y en otras relaciones de bienes posteriores, lo que cabría interpretar como reflejo de una actitud claramente contraria a la aceptación de pagos aplazados en las transacciones protagonizadas por los marqueses a partir de las últimas décadas del Seiscientos. Las dificultades para cobrar los precios de los bienes vendidos a plazos -expresamente mencionadas, hacia 1676, en relación con el ganado de labranza adquirido por los labradores del entorno ${ }^{69}$ - habrían inducido a los titulares de Rafal a rechazar, de forma creciente, el procedimiento de la obligación.

Una vez descritas las lineas esenciales que marcan la trayectoria del patrimonio familiar, interesa detenerse en las formas de gestión y explotación, y muy especialmente en las concernientes a los dominios agrarios, entre los que destacan los señoríos de Rafal y La Puebla, pero sin olvidar las vastas heredades poseídas tanto en la huerta como en el campo.

66. AHO: Protocolos de Juan Liñán, 1644-45; ff. 796-861v.: inventario de bienes realizado por D. Gaspar Rocamora García de Lassa tras el fallecmiento de su madre, $D^{a}$ María García de Lassa, en 1 de septiembre de 1645. Se hacía distinción, en dicho inventario, de las «deudes del llibre vell», que recogía las contraídas entre 1623 y 1632 , algunas de las cuales eran calificadas expresamente como «incobrables».

67. AHO: Protocolos de Juan Liñán, 1648-49-50; cartas matrimoniales de 9 de marzo de 1648.

68. AHO: Protocolos de Bertomeu Roig, 1666; inventario realizado por D. Juan Rocamora García de Lassa, tras la muerte de su hermano, D. Gaspar, en 1, 2, 3, 4, 13, 25 y 27 de septiembre, 24 de octubre y 28 de noviembre de 1666 .

69. AHN: Consejos, Leg. 22.004, 


\section{EL SEÑORÍO Y MARQUESADO DE RAFAL}

Comenzando por el valioso predio que dio nombre al marquesado, el señorío de Rafal, el análisis de las circunstancias que jalonaron su colonización inicial e inmediata conversión en marquesado, por parte de D. Jerónimo, ya fue analizado en otro lugar; por lo que ahora solo cabe recordar, de forma somera, los aspectos más relevantes de ese momento fundacional, para centrarnos en la trayectoria seguida con posteriori$\operatorname{dad}^{70}$. Así, fueron elementos destacados en la configuración inicial del marquesado:

a) La colonización de una parte de la antigua heredad, mediante la cesión de casas y parcelas de tierra en enfiteusis a nuevos pobladores, que habrían de satisfacer censos en dinero no muy onerosos, pero también un elevado derecho de entrada por la casa, consistente en un tercio de su valor estimado

b) La constitución ex novo de una comunidad de vasallos sobre la que el señor se reserva el ejercicio de la jurisdicción, la elección anual de los oficiales municipales, y la explotación de los servicios de tienda, horno, panadería, en régimen de monopolio

c) La coexistencia de estos nuevos pobladores, con sus correspondientes derechos sobre el dominio útil de las tierras y casas recibidas, con un puñado de censatarios antiguos avecindados en municipios del entorno, a los que se intentó presionar para tratar de reconvertirlos a la nueva situación.

d) La reserva señorial de una parte importante del terrazgo, para su explotación por otras vías que no comportaran la cesión del dominio útil.

Quedaba así configurado un proceso colonizador que, en realidad, se desarrolló en dos fases: la primera, entre 1636 y 1638 , fue auspiciada por el fundador del marquesado; la segunda, en 1643, fue impulsada por su sucesor, D. Gaspar, y aunque se presentaba como una continuidad de la anterior, es posible que conllevara algunas modificaciones en las condiciones iniciales. En cualquier caso, a pesar de ignorarse los detalles de la primera, esta última supuso una ampliación del número de enfiteutas $y$, en consecuencia, de la tierra censida. Habiéndose perdido las escrituras originales registradas ante el notario Ginés Martínez -según alegaban las partes contratantes, en $1643-$, en esta fecha fueron firmados un total de 26 establecmientos a otros tantos enfiteutas, pero sólo en 12 de ellos se hacía mención expresa a la existencia de condiciones anteriores, pactadas con D. Jerónimo, que se declaraban vigentes y subsumidas en las nuevas. La omisión de este detalle en las 14 escrituras restantes, no obstante, podría deberse a que -en estos casos- se trataba de nuevos establecimientos, correspondientes a una segunda oleada repobladora. Es posible, además, que ahora participaran también algunos campesinos del entorno que no acabaron de fijar su residencia en Rafal, pues cinco de estos nuevos enfiteutas no recibieron casa -como era norma-, ni siquiera solares para su inmediata construcción, sino únicamente tierras ${ }^{71}$. Quizá el marqués no

70. La información que sigue procede, salvo indicación en contrario, de BERNABÉ GIL, David: «La formación...», pp. 39-43.

71. AHO: Protocolos de Juan Liñan, 1642-43, ff. 349-632, 26 escrituras de establecimientos en enfiteusis, el 24 de enero de 1643. Se incluye transcripción de una de ellas, tomada al azar, en APENDICE 
disponía ya de casas suficientes, o tuviera que plegarse a la voluntad de algunos enfiteutas que preferían continuar residiendo por el momento en sus municipios de origen. La elevada cuantía percibida por la cesión de la casa en concepto de derecho de entrada -un tercio de su valor estimado- $\mathrm{y}$, sobre todo, el capítulo referente a la obligatoriedad de residir en el marquesado, bajo pena de comiso, para todos los que recibían tierras, parece excluir cualquier interpretación basada en un hipotético desinterés señorial por atraer más vecinos, que, además, contibuirían a engrosar los ingresos proporcionados por las regalías.

Si uno de los objetivos inciales consistía en la constitución de una comunidad estable, enrraizada en el marquesado y que fuera capaz de garantizar una mínima renta anual, resultaba primordial la fijación de unos censos en consonancia con los que, en esos momentos, estaban vigentes en otros señoríos del entorno; además de la cesión de parcelas de tamaño adecuado para la supervivencia y reproducción de la familia campesina.

Los censos exigidos por el dominio útil de la tierra no son, en efecto, demasiado elevados, si se tiene en cuenta la calidad de la tierra, toda ella de huerta; y no guardan relación con el tipo de cultivo, pues los 9 sueldos por tahúlla se aplican indistintamente a todas las parcelas. Quizá se trataba, con esta homogeneidad, de estimular futuras transformaciones de cultivos debidas a la iniciativa de los enfiteutas, al menos mientras no comportaran una reducción del arbolado. Así, la única claúsula restrictiva en esta materia aludía a la prohibición expresa de cortar árboles, mientras que se silencia cualquier referencia a la viña.

Y si los censos por la tierra distaban de alcanzar una extrema gravosidad, llegando a representar entre el $4 \%$ y el $8 \%$ de su valor -según los precios alcanzados en posteriores compraventas-, tampoco el canon anual por la casa, fijado en 20 sueldos y una gallina, parece excesivo; aunque en este caso no ha de olvidarse que ya se había pagado previamente, en una vez, un tercio de su valor, como compensación al señor por los gastos de la reciente construccción. Al igual que ocurría con las tierras, también el censo de las casas era homogéneo, si bien el valor de los inmuebles presentaba diferencias significativas, posiblemente más en función de su amplitud que de la calidad de los materiales utilizados. Así, según un justiprecio de las mismas realizado en 1647, el valor de cada inmueble oscilaba entre 55 y 130 libras, aunque la mayoría se situaban en $85 / 90$ y en 120 libras $^{72}$. Por consiguiente, el censo de las casas representaba, por término medio, en torno al $1 \%$ de su valor, a lo que podría añadirse otro 1 ' $7 \%$ procedente del prorrateo en 20 años del derecho de entrada. A partir de estas estimaciones puede entenderse que algunos enfiteutas prefiriesen ceder en arrendamiento sus predios, quizá para dedicarse a otros menesteres, obteniendo un ligero beneficio: así lo hizo en 1647

DOCUMENTAL. En ellas se basa el análisis de las relaciones señoriales que se hará a continuación. 72. AHO: Protocolos de Juan Liñan,1646-47; escritura de 22 de octubre de 1647, ff. 770-774v. 
uno de ellos al arrendar a un tercero el conjunto integrado por tres parcelas y una casa, justamente por el doble de la cuantía de los censos que recaían sobre el mismo ${ }^{73}$.

Además de la cuantía del censo, el tamaño de los lotes de tierra también era un elemento que podía contribuir a la estabilidad del proyecto colonizador, de modo que ningún enfiteuta recibió menos de 20 tahúllas, mientras que uno de cada tres obtuvo más de 30 , siendo la media de $28^{\prime} 44$ por cabeza. Sin llegar a resultar totalmente igualitario, el reparto del dominio útil revela una tendencia a consolidar un campesinado de tipo medio-bajo, relativamente homogéneo, que pudo disponer de la tierra necesaria para la autosuficiencia familiar y poco más. Además, los lotes establecidos solían distribuirse en tres parcelas, con neto predominio de la tierra blanca y una ligera presencia de la viña y -como cultivo de orientación comercial-- del moreral. En total, la primera alcanzaba las 575 tahúllas en los primeros establecimientos de 1643, distribuyéndose el $23 \%$ restante entre el moreral -con 83 '5 tahúllas-y la viña -con 76 tahúllas-, mientras que la participación del olivar resultaba testimonial, con solo 5 tahúllas $^{74}$.

A la consecuención de los objetivos colonizadores iban encaminadas también una serie de estipulaciones contenidas en todos los establecimientos individuales que, en cierto modo, hacían las veces de carta-puebla. Destacan, entre ellas, la obligación de residencia en el señorío (c.13,23); la de atender el cultivo y cuidado de los inmuebles, de modo que solo puedan realizarse mejoras (c. 2, 23); y la prohibición de vender el dominio útil de tierras y casas, en todo o en parte, a forasteros (c.8), ni a eclesiásticos o personas de religión (c.16), y siempre previa licencia del señor, quien se reservaba el derecho de fadiga de 30 dias y de luismo de la décima parte (c. 1, 5, 6, 14). Además de cumplir estos requisitos, los enfiteutas debían asumir los costes de mantenimiento y de mejora de la infraestructura hídrica - pagar las mondas y demás contribuciones de las acequias y azarbes-, como titulares del dominio útil (c.10, 11).

Pero, tan importante como la estrategia de reordenación agraria y poblacional operada en Rafal era, para el señor, procurarse un ámbito de dominio político y jurisdiccional sobre el marquesado. A tal fin se dedicaron algunos artículos de los mencionados establecimientos de 1643, que, en lineas generales, disponían lo siguiente:

- La constitución de una comunidad vecinal, dotada de oficios municipales, como justicia y jurados, nombrados cada año por el señor a partir de una terna propuesta por los vasallos (c.19).

- La reserva señorial de la facultad de conceder licencias a la comunidad para poder imponer sisas u otros impuestos municipales (c. 22)

- La reserva señorial de la jurisdicción, que ejercerá directamente o con su asesor sólo en tercera instancia, tras conceder al justicia el conocimiento de la primera y la segunda, cambiando en este caso de asesor (c.24). Aunque no se dice expresamente que se tratara de la alfonsina, al no incluir el título de marqués ninguna atribución juris-

73. Ibidem; escritura de arrendamiento, el 27 de octubre de 1647, ff. 834-836.

74. Con mayor detalle, en BERNABÉ GIL, David: «Población y estructuras agrarias en el marquesado de Rafal (ss. XVII-XVIII)», comunicación presentada en la $I X$ Reunión Cientifica de la Fundación Española de Historia Moderna, Málaga, 6-8 de junio de 2006 (en prensa) 
diccional superior, hay que descartar cualquiera otra distinta. Por otro lado, el nombramiento de un jurista -el Dr. Luis Mur- como juez delegado del marqués para las causas enfiteuticales, tres semanas después de protocolizados los establecimientos ${ }^{75}$, tampoco añade detalles de interés, pues era práctica común entre los señores directos, aun cuando no ostentaran jurisdicción.

- La obligación de los vasallos de hacer reconocimiento de la señoría directa y renovación del juramento de fidelidad y homenaje, de forma conjunta, cada 5 años, mediante escritura pública (c.18).

- Finalmente, la utilización de los servicios de molino, horno, tienda y taberna, que explotaría el señor en régimen de monopolio (c. 15, 20, 21).

La empresa señorial se completaba-como se ha dicho-con la reserva de una parte importante del terrazgo para su explotación a través de otros regímenes de tenencia que no comportaban la división de dominios; y que -a juzgar por las referencias contenidas en algunos inventarios- perduraron durante bastante tiempo. Así, el estancamiento e incluso retroceso demográfico que experimentó el marquesado durante buena parte del Seiscientos no solo es reflejo de una relativa paralización e inestabilidad del proyecto colonizador, sino que permite intuir una mayor implicación de los marqueses en la gestión indirecta de la explotación agraria del señorío.

Ya en 1645, en plena coyuntura colonizadora, se dejaba constancia de la existencia por cuenta del señor de «tres parells de mules ab sos aparells de llauro en dit lloch $y$ Marquesat de Rafal $\rangle^{76}$ que, sin duda, estarían a disposición de posibles arrendatarios o aparceros. Y en 1666 son expresamente mencionados como residentes en el señorío, además de los enfiteutas, tres labradores que cultivan al quinto y uno más a medias, con un total de 13 animales de tiro y abundantes instrumentos de labranza de propiedad señorial; además de inventariarse una casa grande «per a la habitació dels dits Illustres Marquessos», una bodega, una almazara y cuatro barracas para la cria de la seda ${ }^{77}$. La proporción de tierra cuyo dominio consolidado permanecía por entonces en manos señoriales podía aproximarse a la mitad del marquesado, pues en total se le atribuían al término unas 1.500 tahúllas, entre las cuales también había algunas «saladars». La presencia de este tipo de medianos aparceros ya no se detecta en el inventario de 1691; pero ello no quiere decir que se hubiera extendido la enfiteusis de forma significativa.

Solo unos años más tarde, en el arrendamiento del marquesado realizado en 1694 se incluía, además de la percepción de todos los censos y regalías - con reserva expresa de la jurisdicción y del derecho al nombramiento anual de oficiales-, la explotación agraria del territorio no establecido, conjuntamente con la de una heredad anexa al

75. AHO: Protocolos de Juan Liñan, 1642-43, escritura de 13 de febrero de 1643.

76. AHO: Protocolos de Juan Liñán, 1644-45; ff. 796-861v.: inventario de bienes realizado por D. Gaspar Rocamora García de Lassa tras el fallecmiento de su madre, $D^{a}$ María García de Lassa, en 1 de septiembre de 1645 .

77. AHO: Protocolos de Bertomeu Roig, 1666; inventario realizado por D. Juan Rocamora García de Lassa, tras la muerte de su hermano, D. Gaspar, en $1,2,3,4,13,25$ y 27 de septiembre, 24 de octubre y 28 de noviembre de 1666 . 
mismo, denominada de Arques. En la cesión temporal de la explotación se describía los animales y aperos de labranza con que contaba la casa principal del señorío, así como las existencias en frutos y equipamiento de almazara, bodega y barracas de criar seda; y se establecía la obligación de cultivar 《a uso y costumbre de buen labrador» ${ }^{78}$.

Este carácter mixto que presentaba la gestión del marquesado, como señorio generador de censos enfitéuticos y derechos regalianos, por un lado, pero también como gran explotación agraria en régimen de arrendamiento unitario, por otro, debió mantenerse durante el periodo en que permaneció bajo secuestro, tras la guerra de Sucesión. En 1725, poco antes de firmarse la Paz de Viena, el juez de confiscados del Reino de Valencia conseguía arrendarlo por un precio superior al de treinta años atrás, aun cuando ahora ya no se incluía la heredad contigua de Arques. Frente a las 600 libras anuales en que se concertó el contrato de 1694, en esta ocasión se estipularon 811'8 libras, reflejando así un incremento que traduce tanto la revalorización de la tierra como factor productivo, como la mayor rentabilidad de las percepciones derivadas de las relaciones señoriales. Como había ocurrido décadas atrás, en el arrendamiento se hacía reserva expresa de «la jurisdicción civil y criminal y gobierno de dicho lugar» y también de los luismos -que quedaban para el real fisco-, de modo que la cesión afectaba a «los derechos dominicales y tierras... comprehendiendo el horno, panadería, tienda, taberna, el huerto, la cassa grande y cassas que quedan por establecer en dicho lugar, las quales tierras son parte tierra blanca y parte plantada de moreras y olivos»). El arrendatario quedaría sujeto en la percepción de los censos que recaían sobre las tierras a «lo que consta por los cabreves, que es a quatro y tres reales por tahulla, por quanto se ha entendido que se exsede en este particular»; pero, además, debería de cultivar la tierra no establecida «a uso y costumbre de buen labrador», aplicando a los diversos cultivos las labores agrícolas que se le indicaban de forma expresa a lo largo de varios capítulos, para garantizar su cuidado ${ }^{79}$.

Aunque es difícil saber si durante la etapa de secuestro se amplió la superficie censida, sí lo hizo con toda seguridad tras la recuperación del dominio de Rafal por los marqueses, pues un año antes del fallecimiento de $\mathrm{D}^{\mathrm{a}}$ Jerónima aquélla ascendía a 1.161 '7 tahúllas, registrando un máximo que quizá no volvería a alcanzarse en toda la historia posterior del marquesado ${ }^{80}$. Con ello, es probable que también se viera incrementada la renta global proporcionada por el núcleo señorial, sobre todo en la medida en que la extensión de la enfiteusis hubiera afectado asímismo a las casas habitadas, pues un crecimento del vecindario se traducía en la consiguiente revalorización de las regalías, además de proporcionar ingresos por el derecho de entrada sobre las casas. Y, en efecto, el número de casas habitadas, que en 1691 todavía se situaba en 21, a pesar

78. ACO: Protocolos de Andrés Ximenez, 1694, ff. 326-330v; escritura de arrendamiento, de 24 de agosto de 1694.

79. AHO: Protocolos de Josep Martinez de Rodriguez, 1725; ff. 126-128v; escritura de arrendamiento.

80. BERNABÉ GIL, David: «Población y estructuras agrarias...». 
del crecimiento experimentado desde el mínimo poblacional al que se había llegado hacia 1666 -con sólo 16-, sobrepasaba ya la cuarentena en $1734^{81}$.

Mayor era, para este última fecha, el número de infiteutas con tierras en el marquesado, pues algunos -hasta un total de 18 , que representaban el 30 por ciento del total- tenían su habitación en otras poblaciones del entorno. Quedaba así de manifiesto que la obligación de residencia y la prohibición de vender el dominio útil a forasteros, a pesar de estipularse en los establecimientos iniciales de Rafal, distaron de observarse a raja tabla más adelante, necesariamente con el consentimiento de los marqueses. La cuantía del derecho de entrada que recaía sobre las casas no era precisamente un factor de atracción poblacional, pero tampoco cabe descartar los efectos de una posible estrategia señorial consistente en dosificar las cesiones del dominio útil de la tierra, con tal de conservar al menos una parte del marquesado en dominio pleno. La permisividad señorial con respecto a la obligación de residencia de los enfiteutas -por lo demás, muy generalizada en el setecientos valenciano- contribuía a diluir una excesiva presión campesina sobre el dominio útil de la tierra que, en los pequeños pero valiosos señoríos enclavados en el corazón de la huerta, podía desembocar en la práctica extinción de la reserva señorial. Y, al menos en Rafal, no parece que sus titulares hubieran estado dispuestos a desprenderse íntegra y definitivamente de ella, repartiéndola en su totalidad en enfiteusis, como parece confirmar asímismo la trayectoria posterior del marquesado ${ }^{82}$.

\section{LA BARONÍA DE LA PUEBLA}

La estrategia seguida en el otro señorío que también formaba parte del vínculo de Rafal - la baronía de la Puebla - es otra muestra de esa resistencia, aunque las circunstancias difieren aquí sustancialmente; y, con ellas, las razones de su perduración como dominio pleno desde su fundación hasta su supresión por los decretos abolicionistas.

El núcleo original, en este caso, era una finca de 2.010 tahúllas, cercenadas de una baronía -la Daya Nueva-- en época del primer Marqués, sobre la cual obtuvo muy pronto, además de la propiedad de la tierra -por compra, tras subasta por embargo ejecutivo, en 1620--, la jurisdicción de mero y mixto imperio, a cambio de servicios a la Corona, en 1631. Pero la pronta anexión de otras dos fincas de almarjales anexas -de dimensiones imprecisas y variables, quizá en torno a unas 2.000 y 2.400 tahúllas respectivamente-, permite contemplar el conjunto, de facto, como una unidad patrimonial, por mucho que la condición señorial de estas últimas fuera frecuentemente discutida. En el primer caso, se trataba de un establecimiento municipal de tierras saladares

\section{Ibidem.}

82. Para esa trayectoria posterior, vid. Gil OlCina, Antonio y CANALES MARTinez, Gregorio: Residuos de propiedad señorial en el Bajo Segura. Instituto de Estudios Juan Gil-Albert, Alicante, 1988, pp. 207-212; y en el contexto general del conjunto patrimonial, MILLÁN, Jesús y ZUR!TA, Rafael: «Élites terratenientes y tipos de caciquismo. La casa de Rafal/Viamanuel entre la revolución liberal y la crisis de la Restauración», Historia Agraria, n'16,1998, pp. 153-181. 
y almarjales realizado en favor de D. Jerónimo en 1633 por la ciudad de Orihuela, con «mòdica pensió de cens, fadiga y lloisme y tot altre plen dret enphitèotich» de solo 5 libras anuales y obligación de desecar y reducir a cultivo. En el segundo, se trataba de un lote formado por dos adquisiciones a sendos particulares de 2.000 y 400 tahúllas -también de almarajales en su mayor parte-, realizadas respectivamente en 1628 y 1631 . Por consiguiente, el conjunto formado por estas 6.410 tahúllas aproximadamente, ubicadas en los aledaños del humedal, donde confluía la huerta con el pantano, aunque será tratado como una unidad de explotación, no debe ocultar su diversa consideración dominical y jurisdiccional. Y este cúmulo de circunstancias al que se acaba de aludir habrían de determinar en gran medida su trayectoria posterior ${ }^{83}$.

Así, a diferencia de Rafal, la trayectoria poblacional y colonizadora dibuja en la baronía de la Puebla un estancamiento secular desde su fundación inicial. Si ya la propia obtención de la jurisdicción baronal por parte de D. Jerónimo le eximía de cumplimentar el mínimo poblacional -15 vecinos- requerido por el fuero alfonsino para alzarse con la condición señorial, el vecindario de 1646 recoge únicamente ocho cabezas de familia ${ }^{84}$. Algo más explícita es la información contenida en el inventario de 1666, donde se anota la existencia en la Puebla de «nou palaus y una barraca de adoves...y dos barraques mes de canyes y sisca, ab sos pobladors y vasalls y llauradors y alguns habittadors $\rangle^{85}$. Y esta referencia demográfica no parece que fuera ampliamente superada en las décadas que siguieron, caracterizadas más bien por una cierta estabilidad en el cambio de centuria y durante el secuestro del señorío, con una ligera tendencia a la baja. Si el inventario de 1691 continúa sin especificar el número de casas, los recuentos generales elaborados durante la etapa de secuestro apuntan a un número de vecinos que pudo oscilar en torno a la docena -10 en 1712/13, 12 en $1717^{86}$; pero en el momento de la toma de posesión por restitución de dichos bienes, en 1725, se hace mención expresa de sólo 7 casas y dos barracas ${ }^{87}$. Un padrón de 1735 registra ya solo «cinco contribuyentes y un pobre», como únicos vecinos ${ }^{88}$, y sendas escrituras de arrendamiento suscritas en 1736 y 1741 mencionan «una casa principal y cuatro medianas $\rangle^{89}$. Tan corta población hacía poco rentable la fugaz presencia - si cs

83. Sobre el origen de La Puebla y vicisitudes posteriores, que no repetiré aquí, vid. BERNABÉ GIL, David: «la formación...... », pp. 32-39

84. Millán y García-VARela, Jesús: Rentistas y campesinos..., p. 26

85. AHO: Protocolos de Bertomeu Roig, 1666; inventario realizado por D. Juan Rocamora García de Lassa, tras la muerte de su hermano, D. Gaspar, en $1,2,3,4,13,25$ y 27 de septiembre, 24 de octubre y 28 de noviembre de 1666.

86. Millán y García-Varela, Jesús: Rentistas y campesinos...., p. 143.

87. AMM: Colección Alegria: Caja 39, N² 287: Memorial ajustado....del pleito seguido por los Maryueses de Rafal...con los administradores de las Reales Pias Fundaciones..., f. 26.

88. Camarena MahiQues, José: Padrón demográfico-económico del Reino de Valencia. 1735, Anubar, Valencia, 1966, p. 67.

89. AHO: Protocolos de Josep Martinez de Rodriguez, 1736; escitura de arrendamiento, de 12 de septiembre de 1736; ff. 282-286; Protocolos de Josep Martinez de Rodriguez, 1741; escritura de arrendamiento de 2 de enero de 1741 . 
que llegó a haberla alguna vez- de servicios como horno, panadería, carnicería, tienda y taberna, que solo son expresamente mencionados en el inventario de $1645^{\circ 0}$, para desaparecer en adelante cualquier rastro de ellos.

Esta evolución demográfica, que contrasta con la experimentada por Rafal, es consecuencia de una doble circunstancia. Por un lado, guarda estrecha relación con la inexistencia de la enfiteusis como elemento de atracción colonizadora, ya desde sus inicios. La inmediata adquisición del mero y mixto imperio por parte de D. Jerónimo, además de disipar cualquier posible duda sobre la condición jurisdiccional de la base territorial sobre la que se asentaba el nuevo señorío -desgajado de una baronía-, relevaba al titular de cualquier obligàción colonizadora que conllevara concesiones de dominio útil. Y en el inventario de 1639 , en efecto, no hay referencias a regímenes de tenencia que comporten división de dominios. Sí se menciona, en cambio, la existencia de bueyes «per a la llauro de les dites tafulles de la Baronia de la Puebla, ab los quals les llauran quatre llauradors quinters, ab dos parells cascu» ${ }^{9 !}$. En el inventario de 1645 , las referencias continúan siendo difusas, aunque ahora se especifica el número de 32 "bous de llauro ab tots sos aparells»" ${ }^{92}$. Y en de 1666 tampoco se alude a la existencia de establecimientos, enfiteutas, ni censos; sino, una vez más, a la de cuatro «llauradors quinters que llauren ab bous», que se reparten un total de 35 cabezas, 10 arados, 15 rejas y demás aparejos ${ }^{93}$.

Ahora bien, la diversidad de categorias expresamente señaladas en el inventario de 1666, cuando se alude a los ocupantes de las casas y barracas de la Puebla como «pobladors y vasalls y llauradors y alguns habitadors» permite entrever que quizás no toda la baronía era cultivada mediante un régimen de tenencia homologable de aparcería al quinto. Tampoco otros documentos arrojan suficiente luz sobre otras posibles fórnulas complementarias, pues no se conocen escrituras de arrendamiento de la baronía anteriores a la etapa en que estuvo bajo secuestro, pero la diferencia entre el número de residentes y el de «labradores quinteros» hace pensar en la condición de jornaleros de algunos de aquéllos.

Durante la etapa de secuestro, la baronía fue arrendada, conjuntamente con la heredad contigua de la Era Alta, por periodos de 6 años - en 1713 y 1719-, y así continuó practicándose tras su recuperación por los marqueses -en 1726, 1731, 1736 y 1741-, sin que en ningún momento las escrituras correspondientes mencionen elemen-

90. AHO: Protocolos de Juan Liñán, 1644-45; ff. 796-861v.: inventario de bienes realizado por D. Gaspar Rocamora García de Lassa tras el fallecmiento de su madre, D María García de Lassa, en 1 de septiembre de 1645.

91. ACO: Protocolos de Ginés Martinez, 1636-39; Inventario de bienes realizado por Da María García de Lassa tras el fallecimiento de su marido, D. Jerónimo Rocamora y Thomás, en 7 de noviembre de 1639

92. AHO: Protocolos de Juan Liñán, 1644-45; ff. 796-861v.: inventario de bienes realizado por D. Gaspar Rocamora García de Lassa tras el fallecmiento de su madre, Da María García de Lassa, en 1 de septiembre de 1645 .

93. AHO: Protocolos de Bertomeu Roig, 1666; inventario realizado por D. Juan Rocamora García de Lassa, tras la muerte de su hermano, D. Gaspar, en $1,2,3,4,13,25$ y 27 de septiembre, 24 de octubre y 28 de noviembre de 1666 . 
tos que permitan sospechar la existencia, ya no de censos enfiteúticos -como ocurría con Rafal--, sino de tan siquiera aparceros. En todas aquéllas el arrendatario se comprometía a cultivar a uso y costumbre de buen labrador y practicar una serie de labores agrarias específicas -como era habitual en las escrituras de arrendamiento de cualquier finca del realengo-, y a respetar el ejercicio de la jurisdicción, que era expresamente reservada - para el Rey, en las dos primeras fechas; para los Rocamora, en las restantes-, sin que haya mención alguna a regalias y monopolios ${ }^{94}$.

No obstante esta última ausencia, la persistencia de pobladores durante todo el periodo considerado plantea el problema de las condiciones que regulaban las relaciones de aquéllos con la propiedad de la tierra, y si hubo alguna transformación. Y es que, a pesar de su corta población y de la precariedad de los derechos vecinales sobre la tierra, la Puebla contó con autoridades municipales -justicia y dos jurados en el siglo XVII, alcalde ordinario y alguacil mayor desde los decretos de Nueva Planta-, nombradas anualmente por el señor ${ }^{95}$. Tal precariedad pudo traducirse en una elevada movilidad del campesinado residente, posiblemente oculta tras la aparente estabilidad demográfica secular, pero a la que parece apuntar algún hecho puntual, como el desavecindamiento, en 1734 , de quienes venían ocupando a la sazón los oficios de alcalde ordinario y alguacil mayor ${ }^{96}$.

Si la inexistencia de enfiteusis, como resultado de una determinada estrategia señorial, contribuye a explicar el estancamiento demográfico de la baronía, los condicionantes naturales de la zona en que ésta se inscribía facilitaron bastante la viabilidad de la opción elegida. La ubicación de la Puebla - y de los terrenos apropiados en sus inmediaciones- en un paraje colindante con un extenso humedal, de límites móviles e imprecisos -en función de las oscilaciones climatológicas- la hacían especialmente propicia para un tipo de explotación económica distinto y más diversificado que en el caso de Rafal, basado en una combinación de agricultura intensiva de cereal y moreral -en la parte más seca- y extensiva de arroz, ganadería mayor y plantas de crecimiento espontáneo y uso industrial como la sosa, en la zona anfibia. Además, la presunta insalubridad de un terreno de tales características -en la típica asociación, propia de la

94. AHO: Protocolos de Josep Martínez de Rodríguez, 1709-10-11-12-13, escritura de arrendamiento, de 24 de diciembre de 1713, ff. 165-169v; AMM: Colección Alegria; Caja 39, № 287: Memorial ajustado...del pleito seguido por los Marqueses de Rafal...con los administradores de las Reales Pías Fundaciones..., f. 57; AHO: Protocolos de Bernabé Aniorte, 1726, escritura de arrendamiento de 4 de enero de 1726, ff. 4-9; Protocolos de Bautista Ramón, 1731, escritura de arrendamiento de 24 de julio de 1731, ff. 323v326; Protocolos de Josep Martinez de Rodriguez, 1736; escitura de arrendamiento, de 12 de septiembre de 1736; ff. 282-286; Protocolos de Josep Martinez de Rodriguez, 1741; escritura de arrendamiento de 2 de enero de 1741 .

95. Ejemplos de este tipo de nombramientos en AHO: Protocolos de Bertomeu Roig, 1670, escritura de 25 de abril de 1670; Protocolos de Bautista Alemán, 1732, escritura de 4 de julio de 1732, ff. 66-66v; Protocolos de Bautista Alemán, 1734, escritura de 16 de agosto de 1734, ff. 107-107v.

96. AHO: Protocolos de Bautista Alemán, 1734, escritura de 16 de agosto de 1734, ff. 107-107v. 
época, del humedal con el paludismo-, tampoco actuaba precisamente como factor de atracción demográfica ${ }^{97}$.

La tradicional dedicación ganadera de buena parte de las tierras anexas a la Puebla, e incorporadas de facto a la baronía hasta la disputa suscitada por Belluga -a partir de 1724- al frente de las Pías Fundaciones, queda recogida en la práctica totalidad de testimonios que declararon por ambas partes en los pleitos suscitados tras la restitución de los bienes secuestrados ${ }^{98}$. Los testigos discrepaban, no obstante, en el alcance de los avances del proceso desecador ${ }^{9 \%}$.

Para algunos, interesados en abonar la idea del incumplimiento, por parte de los marqueses, de las obligaciones desecadoras y roturadoras contraidas en el establecimiento municipal de 1633, se trataría de mostrar la abundancia de ganado mayor y menor que deambulaba por la zona antes de iniciarse la guerra, como prueba irrefutable de su nula o escasa dedicación agraria. Además de corroborar que el único aprovechamiento obtenido por los marqueses en el entorno de la Puebla consistía en «la sosa y el pasto para las yeguadas y vacadas», un testigo afirmaba haber presenciado la entrada «en barca» en dicho paraje a cazar patos y otras aves, así como la existencia de «una pesquera de anguilas en una laguna». Y no faltaba quien relataba, incluso, la oposición del último marqués a las obras de desecación iniciadas por un vecino en tierras colindantes, pues cuando éste «empezó a escorredorarlas y labrarlas y habiendo procurado impedir el paso de las toradas y yeguadas que el Marqués de Rafal y otros tenían en las tierras de dicha majada, pasó con gente el dicho Marqués a cegar y tapar dichos escorredores que había abiertos para el desagüe de las tierras y pasturó con dichos sus ganados»

Los testigos de la parte contraria, aunque ponderaban el significativo avance del cultivo en el paraje cedido por la ciudad de Orihuela al primer marqués, no dejaban de admitir que las «utilidades» proporcionadas por la presencia de ganados eran en algunas zonas superiores a las que podían obtenerse mediante la reducción a cultivo de tierras pantanosas de difícil y costosa -tanto desde el punto de vista técnico como económico - desecación. El aumento de los diezmos, como objetivo expresamente señalado en la cesión municipal, se conseguía, por tanto, mediante una óptima combinación de ganadería y agricultura. $Y$ en esa dedicación preferentemente ganadera se incluía no solamente a la abundante cabaña de los marqueses de Rafal, sino también -de creer algunas versiones interesadas en mostrar la condición «baldía», «realenga»y, en con-

97. Bernabé GIL, David: «Insalubridad....». En cualquiera de los arrendamientos de La Puebla, mencionados en supra, nota 94 , hay referencias a los cultivos existentes en la baronía.

98. Sobre estos pleitos, vid. LEÓN ClosA, T: «Aportación al estudio de la colonización de la Vega Baja del Segura», en CREMADES GrIÑÁN, Ma del Carmen (ed.): Estudios sobre el Cardenal Belluga, Academia Alfonso X el Sabio, Murcia, 1985, pp. 224-225; sobre la obra colonizadora de Belluga, además de Ibidem, pp. 211-268, vid. también MILLAN y GARCIA-VARELA: Rentistas y campesinos..., pp. 176-192.

99. Salvo indicación en contrario, la información que sigue procede de AMM: Colección Alegria; Caja 39, No 287: Memorial ajustado... del pleito seguido por los Marqueses de Rafal...con los administradores de las Reales Pias Fundaciones..., 
secuencia «comunal» de algunos parajes supuestamente usurpados por la señoría- a los abastecedores de las carnicerías de Orihuela y demás pueblos comarcanos y de otros particulares, en general.

El cultivo del arroz en las zonas más próximas al almarjal, finalmente, también es mencionado de forma unánime en los testimonios aludidos; asi como el aprovechamiento de la sosa que crecía libremente en los saladares, cuyo arrendamiento llegaba a proporcionar entre 60 y 90 libras anuales durante el segundo cuarto del Seiscientos ${ }^{100}$.

En comparación con las rentas generadas por el marquesado de Rafal, la baronía de la Puebla y almarjales anexos, con una extensión efectiva del cultivo muy superior, pero que no llegaba a duplicar aquél -quizá unas 2.100 tahúllas, como se afirmaba en 1666 y 1691, o algunas más, después de la guerra-, proporcionaba unos ingresos también algo más cuantiosos. Además del pasto obtenido de forma gratuita para el ganado mayor -de imposible traducción en valores monetarios- mientras se mantuvo la cabaña ganadera, el término originario de la Puebla se arrendó conjuntamente con la heredad de la Era Alta -de unas 130 tahúllas- en 1713 por 700 libras de moneda y 100 cahices de trigo, cuyo valor en el mercado podía alcanzar otras 700 libras más ${ }^{101}$. $\mathrm{Y}$ en torno a estas cantidades se mantuvo en los años siguientes el arrendamiento conjunto de ambas fincas, pues en 1719 se adjudicaron por 776'6 libras más 100 cahices de trigo, en 1726 por $742^{\prime} 6$ libras y 100 cahices de trigo, y aunque en dos escrituras posteriores -1731, 1736- descendió a 600 libras, más el trigo acostumbrado, los arrendatarios asumieron la obligación de plantar a su costa un buen número de morerales: 800 unidades, en 1731; 50 tahúllas en $1736^{102}$. Y si el rendimiento producido por la baronía superaba el del marquesado, también lo hacía su valor estimado, pues según las cartas matrimoniales de 1691 aquél era evaluado en 40.000 libras, frente a las 30.000 atribuídas a Rafal.

La estrategia señorial con respecto a La Puebla era, por tanto, muy distinta de la seguida en Rafal. Sus condicionantes naturales, pero también la incidencia de esas peculiaridades de carácter jurisdiccional y territorial en su gestación y evolución aconsejaban la práctica de un modelo distinto de explotación. De hecho, llegó a funcionar como una gran finca con un dominio señorial consolidado sobre todo el territorio, en régimen de coto redondo.

100. AHO: Protocolos de Bertomeu Roig, 1663; escritura de arrendamiento, el 5 de marzo de 1663, de la sosa de los saladares de La Puebla a 4 vecinos de Elche. Protocolos de Bertomeu Roig, 1671; escritura de arrendamiento, el 13 de mayo de 1671 , de la sosa de los saladares de La Puebla a un mercader de Guardamar.

101. AHO: Protocolos de Josep Martínez de Rodríguez, 1709-10-11-12-13, escritura de arrendamiento, de 24 de diciembre de 1713, ff. $165-169 \mathrm{v}$.

102. AMM: Colección Alegria: Caja 39, № 287: Memorial ajustado... del pleito seguido por los Marqueses de Rafal . con los administradores de las Reales Pias Fundaciones..., f. 57; AHO: Protocolos de Bernabé Aniorte, 1726, escritura de arrendamiento de 4 de enero de 1726, ff. 4-9; Protocolos de Bautista Ramón, 1731, escritura de arrendamiento de 24 de julio de 1731, fr. 323v-326; Protocolos de Josep Martinez de Rodriguez, 1736; escritura de arrendamiento, de 12 de septiembre de 1736; ff. 282-286; Protocolos de Josep Martinez de Rodriguez, 1741; escritura de arrendamiento de 2 de enero de 1741 
El conjunto integrado por las 2.010 tahúllas originales de La Puebla, las 2.400 tahúllas adquiridas en el paraje anexo de la Majada Vieja y el establecimiento municipal contiguo - de otras 2.000 tahullas - habría de experimentar un sensible recorte, no obstante, a raiz de la iniciativa colonizadora emprendida por el cardenal Belluga a partir de 1724, cuando aun se hallaba aquél bajo secuestro. La disputa iniciada apenas devuelto el patrimonio incautado a los marqueses tardaría años en resolverse de forma definitiva, pero ya desde un primer momento las concesiones reales y municipales en favor de las Pías Fundaciones ocasionaron una amputación de una parte de los humedales que, hasta esos momentos, los marqueses de Rafal habían considerado integrados en sus dominios ${ }^{103}$.

\section{GESTIÓN Y EXPLOTACIÓN DE LAS HEREDADES DE REALENGO}

Más no toda la riqueza patrimonial de la Casa de Rafal descansaba en los dos señoríos mencionados. Si, conforme avanzaba el siglo XVII, fue creciendo el número de fincas ubicadas en el realengo, su gestión y explotación también debió ser materia de atención para los sucesivos titulares. En principio, la documentación notarial, aunque puede resultar idonea para conocer las condiciones de explotación a través de determinadas formas contractuales -como el arrendamiento-, adolece del inconveniente de silenciar otras fórmulas alternativas que no comportaban gestión indirecta - como el cultivo por cuenta propia o incluso bajo determinadas formas de aparcería. Pero, al primar aquéllas -lo que introduce un importante sesgo, a tener en cuenta-, su omisión tampoco puede ser tomada, sin más, como indicio de un hipotético predominio de estas últimas; lo que aconseja prudencia a la hora de valorar el desigual impacto de una y otra en las diversos periodos cronológicos.

Con las debidas precauciones, por tanto, el relativo fracaso de los sondeos realizados en diversos notarios del Seiscientos en busca de escrituras de arrendamiento de las heredades poseidas por los marqueses, junto a las referencias contenidas en los inventarios de la época, permiten aventurar un predominio de la explotación directa de las grandes fincas mediante aparceros al quinto y, en otros casos, mediante los denominados «labradores de aniaga». Contrariamente a esta apreciación, en el inventario de 1639 se hace mención expresa a la figura del arrendamiento en el caso de una finca de 65 tahúllas en la Puerta de Murcia -por 230 libras cada año- y de la cañada de secano de las Salinas - a razón de 45 libras anuales ${ }^{104}$. También se ha podido localizar una escritura de arrendamiento de esta última, para 1651 -por 6 años y sólo 24 libras cada

103. León Closa, T: «Las colonizaciones...», pp. 224-225; AMM: Colección Alegria; Caja 39, № 287 : Memorial ajustado.... del pleito seguido por los Marqueses de Rafal...con los administradores de las Reales Pías Fundaciones.. , pássim

104. ACO: Protocolos de Ginés Martínez, 1636-39; Inventario de bienes realizado por Da María García de Lassa tras el fallecimiento de su marido, D. Jerónimo Rocamora y Thomás, en 7 de noviembre de 1639 . 
uno $^{105}-$; y otra referente a una parcela de moreral de 10 tahúllas, para $1669^{106}$. Pero en el inventario de 1666 , que recoge un mayor número de heredades, queda constancia del predominio de la aparcería.

Así, en la heredad de «la Era Alta», de 270 tahúllas de huerta, había un labrador «al partit», que disponía de una casa, tres barracas, 12 bueyes, dos arados, dos rejas, un legón y demás útiles de labor; en la «de Ocaña», con 700 tahúllas, el «llaurador quinter» habitaba en una barraca «que es de caña y sisca y los pilars son de algeps $y$ pedra», y cultivaba la tierra con 10 bueyes, 2 arados, 4 rejas y demas «aparells de llauro»; en la «cañada de las Salinas», que tras varias incorporaciones recientes alcanzaba ya las 2.000 tahúllas, de las cuales 70 eran de viñas y olivares, eran expresamente mencionados dos «llauradors quinters», con sus correspondientes bueyes -14 y 10 , respectivamente- $y$ utensilios de labranza -cuyo número y tipología se detallaba ${ }^{107}$. Y una década más tarde, la situación no había cambiado sustancialmente. Cuando en 1677 la viuda de D. Gaspar fue a tomar posesión de la heredad de Ocaña, halló en ella dos «labradores quinteros» que, proclamando su fidelidad al marqués, se negaron a obedecer; y también eran «labradores puestos por el Marqués»-su cuñado, D. Juan- quienes estaban a cargo de las fincas de la Era Alta y la cañada de Salinas. En esta última, no obstante, se precisaba que el labrador «percibe cada mes su aniaga, esto es que consiste en una y tantas barchillas de trigo», lo que induce a pensar que quizá no se trataba ya exactamente de un aparcero, sino más bien de un asalariado retribuido en especie ${ }^{108}$.

De admitirse el predominio de la aparcería al quinto, como forma de explotación agraria más extendida en las grandes heredades durante el siglo XVII, la estrategia de los marqueses habría consistido en aportar los medios de producción, involucrar a un labrador de tipo medio en la gestión del proceso de cultivo, compartir los riesgos que su desarrollo comportaba y participar directamente en la comercialización del producto obtenido. Esta opción económica, de gran arraigo en la comarca -incluso en antiguos señorios de jurisdicción civil-, podía resultar idónea para el propietario en coyunturas marcadas por el alza de precios, pero al no concurrir precisamente esta circunstancia durante la segunda mitad del Seiscientos, posiblemente vino determinada más bien por la escasez relativa de grandes arrendatarios capaces de afrontar por sí solos la experiencia productiva.

Durante el siglo XVIII, sin embargo, se hacen más frecuentes las escrituras de arrendamiento, lo que puede ser indicio de la extensión experimentada por esta modalidad contractual en el régimen de explotación de las grandes heredades. Ya durante la época en que éstas estuvieron bajo secuestro debió acudirse al arrendamiento como fórmula adecuada para obtener rentabilidad del patrimonio confiscado, pues evitaba

105. AHO: Protocolos de Bertomeu Roig, 1651, escritura de arrendamiento, de 30 de enero de 1651

106. AHO: Protocolos de Bertomeu Roig, 1669, escritura de arrendamiento, de 22 de febrero de 1669.

107. AHO: Protocolos de Bertomeu Roig, 1666; inventario realizado por D. Juan Rocamora García de Lassa, tras la muerte de su hermano, D. Gaspar, en $1,2,3,4,13,25$ y 27 de septiembre, 24 de octubre y 28 de noviembre de 1666

108. AHN: Consejos, Leg. 22.004, exp. 9. 
someter su gestión a una estrecha vigilancia que, en tales circunstancias, resultaba difícil de llevar a cabo. Y, tras la devolución de los dominios, el rentismo continúa ganando posiciones frente a otras actitudes tradicionales que comportaban una mayor implicación del propietario en la gestión.

Aun no había finalizado el año de 1725 cuando el apoderado del marqués formalizó un total de siete escrituras de arrendamiento, relativas a otras tantas heredades, por un tiempo de sólo ocho meses, a correr desde el primero de noviembre, y hasta finales de junio de 1726. Aunque no hay datos para probarlo, en la mayor parte de los casos es posible que los arrendatarios fueran los mismos que las venían usufructuando con anterioridad a la Paz de Viena, pues no hay precedentes de contratos de arrendamiento de tan corta duración ${ }^{109}$. De hecho, durante el año 1726 se concertaron otros diez arrendamientos, correspondientes a 13 fincas de los marqueses -entre grandes y pequeñas, y sin contar las pertenecientes al vínculo de Benejúzar-; pero ahora la duración establecida osciló entre cuatro y seis años, aunque en la mayoría de los casos comenzaba a correr también desde el primero de noviembre de $1725^{110}$. Y en los años siguientes continuaron los arrendamientos. De 1729 se conocen trece escrituras, concernientes a 18 fincas $^{111}$; y entre 1734 y 1735 fueron suscritas otras dieciseis, alusivas a 19 fincas ${ }^{112}$. Para 1741, finalmente, eran diecisiete el total de fincas agrarias arrendadas, constitutivas de la casa de Rafal ${ }^{113}$-mención aparte, por tanto, de las integrantes del vínculo de Benferri, a la sazón ya bajo el mismo titular.

El análisis realizado a partir de estas 56 escrituras de arrendamiento del periodo 1726-1741 -excluídas, por su carácter atípico, las siete de 1725-, correspondientes a un total de 27 fincas distintas, que representan la práctica totalidad de las posesiones

109. AHO: Protocolos de Bernabé Aniorte, 1725, ff. 219-221v, 227-249; escrituras de arrendamiento de 20, 22,28 y 29 de diciembre de 1725. Fueron suscritas por D. Francisco Rocamora y Cascante, dean de la catedral de Orihuela, como apoderado del marqués consorte, y futuro derecho habiente del título de Rafal, en virtud de poderes otorgados en la ciudad de Milán el 3 de junio de 1725.

110. AHO: Protocolos de Bernabé Aniorte, 1726; ff. 64-70v, 162-175v, 178v-200v, 297-218v; escrituras de arrendamiento de 4 y 26 de enero, 20,21, 22 y 23 de mayo de 1726 . Las dos primeras aun fueron suscritas por el apoderado del marqués consorte; las de mayo, por este último, tras su regreso del exilio, hallándose a la sazón en su señorío de Benejúzar. Las discrepancias entre el número de escrituras y el de fincas se debe a que dos arrendatarios recibieron varias unidades de explotación, generalmente de escaso tamaño.

111. AHO: Protocolos de Bautista Ramón, 1729, ff. 271-273, 285-297, 304-309, 335-340v, 379-384v, 390392 , escrituras suscritas a lo largo del mes de agosto de 1729 . También ahora fueron agrupadas varias fincas pequeñas en dos lotes para su cesión a dos arrendatarios.

112. AHO: Protocolos de Bautista Aleman, 1734, ff. 100-101, 126-127v, 132-136, 155-156v, 160-161v, 170-17Iv, I 82-183v, 188-189v, 195-198v, 200-205v, escrituras suscritas entre los meses de septicmbre, octubre y noviembre de 1734; Protocolos de Bautista Aleman, 1735, ff. 51-52, 153-154v, escrituras de 7 de febrero y de 23 de octubre de 1735.

113. AHO: Protocolos de Josep Martinez de Rodriguez, 174l, ff. 1-140v; escrituras de arrendamiento suscritas entre el 2 de enero y el 3 de febrero de 1741. También en este caso se englobaron varias fincas menores en dos arrendamientos, pero, inversamente, otras dos de gran tamaño se fraccionaron entre dos y tres arrendatarios, respectivamente. 
de los marqueses en el realengo, permite establecer una serie de consideraciones acerca de las estrategías seguidas en relación con la gestión y explotación de sus dominios; pero también de las circunstancias que pudieron influir en aquéllas. Por un lado, es destacable el mantenimiento íntegro de las grandes unidades de explotación, mediante su cesión a un único arrendatario, al menos en todos los casos correspondientes al periodo incialmente considerado. Las excepciones a esta norma, consistentes en la fragmentación de algunas fincas en dos o en tres trozos iguales, para su arrendamiento por separado -que afectan, respectivamente, a la heredad de $\mathrm{D}^{\mathrm{a}}$ Ines, de 600 tahúllas de riego; y a la unidad formada por la Casa Grande y Caseta de Cascante, de 1.000 tahúllas- se producen siempre en 1741, pero no antes. Cobra relieve, por tanto, la figura del mediano o gran arrendatario que, a diferencia de los quinteros del siglo XVII, ahora ha de invertir algo más de capital propio en la empresa agraria que ha de gestionar de forma temporal. No hay constancia, en efecto, de que los arrendatarios o conductores -como también se les denomina a menudo- de estas grandes heredades reciban bueyes ni aperos de labranza; sino únicamente, allí donde las hay, casa o barraca.

Sobre la forma de practicar el cultivo, los contratos suelen especificar-además de las típicas menciones al «uso y costumbre de buen labrador», y al pago de mondas de los edificios de riego, excepto obras nuevas, que corren a cuenta del propietario- el sistema de cultivo de año y vez en la huerta y el del tercio en el secano, para el cereal, prohibiendo su siembra en parcelas de árboles y plantados. Tampoco podrán «echar panizos en rastrojos, sino en barbechos», ni «sacar el estiercol y pajas que se hiciere en dicha heredad, sino es consumirle en sus tierras». Suele estipularse asímismo la obligación de los conductores de reponer a sus expensas los árboles que se secaren, e incluso, a veces, de plantar un número determinado de morerales $\mathrm{y}$, más excepcionalmente, de viñas; además de dejar el último año ciertas extensiones de alfalfa y de sábanas de paja -como alimento del ganado de labor- para el conductor entrante. Con todo ello, se trataba de evitar la depreciación de las fincas, de fomentar la extensión del moreral e incluso del viñedo $-\mathrm{y}$, con ello, su revalorización- $\mathrm{y}$ de asegurar un cultivo adecuado, al tiempo que dejarlas en óptimas condiciones de uso para los nuevos arrendatarios. En caso de que la negligencia del conductor pusiera en peligro estos objetivos, no solo resultaría imposible la renovación del contrato, sino que incluso podría ser objeto de demanda. Así ocurrió en 1731, con los herederos de quién cinco años y medio atrás había arrendado la baronía de la Puebla con la heredad contigua de la Era Alta. Al pretender aquéllos que la marquesa les renovara el contrato por otros seis años, ésta no solo se negó, sino que inició instancias ante los tribunales, alegando que no habían cuidado ni cultivado la tierra del modo estipulado y que se habían ocasionado perjuicios a los plantíos. Finalmente, pudo llegarse a un acuerdo, renunciando ambas partes a las acciones judiciales; pero la nueva escritura suscrita en favor de aquéllos, que respetaba las condiciones iniciales, se estipuló por un periodo de solo dos años ${ }^{114}$.

114. AHO: Prolocolos de Bantista Ramón, 1732, escritura de 9 de marzo de 1732, ff. 135-142v. 
En cuanto a la forma de hacer efectiva la renta, suele establecerse el pago en dinero sólo para las fincas más pequeñas, aunque valiosas por su ubicación en el corazón de la huerta, y con una elevada presencia del moreral. Esta modalidad, sin embargo, no está muy extendida en las grandes heredades de regadío, donde predomina claramente la entrega de un volumen determinado de trigo. En las fincas de secano es más frecuente la partición de frutos al séptimo $\mathrm{y}$, más tardiamente --cuando ya hay viñas u olivos en plena producción-, combinada con una cantidad en metálico. Muy difundida estuvo también, sobre todo en las grandes heredades del regadío y en fecha tardía, la obligación de entregar un cerdo anual o, en su defecto, 10 libras de moneda, que, aun asimilándose a las típicas adehalas señoriales, puede interpretarse aquí, dada su cuantía, como un alza encubierta de la renta ${ }^{115}$. La diversidad que adopta la forma de la renta refleja, así, su adecuación al potencial productivo y a la orientación comercial de las diferentes unidades de explotación agraria. Pero tampoco es ajena a los intereses y perspectivas de los propietarios, que podían beneficiarse directamente del alza de los precios del cereal, al tiempo que compartir riesgos en las grandes heredades de secano, de cosecha extremadamente incierta, dadas las características de la pluviosidad de la zona.

Finalmente, la duración media de los contratos, de seis años, entra dentro de lo habitual en las coordenadas de espacio y tiempo en que se producen, mientras que los únicos cambios reseñables que parecen detectarse entre las escrituras más antiguas -las de 1726-y las más recientes -las de 1741-solo apuntan a una ligera alza de la renta, que afectaría a unas cuantas heredades, debido a circunstancias concurrentes en cada caso, relativas en gran medida a la ampliación de cultivos comerciales: Así, las Sahurdas, la Casa Alta y la Casa Grande de Salinas, añaden dinero a la tradicional partición de frutos -o incrementan su cuantía-, al haberse ampliado la superficie dedicada a viñas y olivos, y por la recolección de sosa. Mención aparte del cerdo -o las 10 libras sustitutorias - que comienza a introducirse en algunas fincas, las Añoras de la Puerta de Murcia y la Caseta de Tell también experimentan un crecimiento de la renta; al igual que la Torre de Cascante y la heredad de D. Felipe Ocaña, donde dicha alza se combina con sendas transformaciones -pero en sentido inverso- en la modalidades de pago. En general, la renta en dinero apenas gana protagonismo frente a otras modalidades que implican una participación del propietario en la producción; al menos, allí donde impera el cereal.

En cuanto a la rentabilidad de estos predios no señoriales, la ausencia de relaciones completas para un mismo año, junto al protagonismo de las percepciones en especie, impiden ofrecer una valoración de conjunto; de modo que hemos de conformarnos con algunas estimaciones aproximativas. Contamos para ello con ese más de medio centenar de escrituras de arrendamiento comprendidas entre 1726 y 1741 , referentes a

115. Sobre el concepto de adehala, vid. Glu Olcina, Antonio: La propiedad...., p. 37. Sorprende de esta obligación su tardía aparición en el realengo, pues está totalmente ausente de los arendamientos suscritos en 1726. Acerca de su carácter es ilustrativa su consideración como derecho personal, pues cuando en 1741 se fragmentan las heredades de $D^{a}$ Inés y Casa Grande de Cascante en dos y tres arrendamientos distintos, respectivamente, cada uno de los cinco «conductores» ha de satisfacer el cerdo correspondiente. AHO: Protocolos de Josep Martinez de Rodríguez, 1741, ff. 20-30, 61-66v, 96-111v. 
un total de 27 propiedades rústicas, que representan la casi totalidad de las integrantes del mayorazgo de Rafal a la muerte de $\mathrm{D}^{\mathrm{a}}$ Jerónima, con algunas otras de libre disposición que ésta reconoce como propias en su testamento de 1736, incluídas las que su heredera consideraba procedentes del llamado «mayorazgo de Cascante». Puesto que la mayor parte de las fincas no se arrendaban en dinero, para las que pagaban en trigo se ha calculado su precio a razón de 8 libras el cahiz, que era la media interanual alcanzada en el mercado alicantino para todo el periodo ${ }^{116}$. Más difícil resulta calcular la producción de las fincas que satisfacían partición de frutos al séptimo, pues al ser todas ellas de secano, las fluctuaciones debía ser considerables. Varios indicios permiten aventurar, no obstante, una productividad teórica media en torno a los 20 cahices por cada 100 tahúllas cultivadas. Este cociente obtenido para el secano, sin embargo, ha de aplicarse solamente al 30 por ciento de la extensión total de cada finca, al estipularse frecuentemente en los contratos de arrendamiento la división de aquélla en tres «barbechones» y hacerse referencia, por otro lado, además de al trigo, también a la cebada, cuya productividad y precio resultaba inferior.

A partir de estas consideraciones e incluyendo el valor de 11 cerdos - a 10 libras por cabeza-, correspondientes a las heredades que -en los arrendamientos de 1729 , 1734/35 y 1741- satisfacían esta suerte de adehala, la renta estimada de las 27 propiedades rústicas ubicadas en el realengo se situaría en torno a las 4.300 libras anuales, de las cuales 3.591 -el 84 por ciento- procedían de las ubicadas en la huerta. Las fincas irrigadas, que abarcaban un total de 4.310 tahúllas, sólo representaban, sin embargo, el 35 por ciento de la extensión total, frente a las 8.180 que abarcaban las de secano, y que proporcionaban una renta estimada en torno a las 700 libras anuales. La renta media de las heredades de huerta -en torno a los 16'7 sueldos por tahúlla- era, por consiguiente, diez veces mayor que la obtenida en el secano; y, lo que resulta más significativo, superaba asímismo, aunque por escaso margen, la proporcionada por la propiedad señorial, en ambos casos ubicada en la huerta.

Claro está que en la rentabilidad de los señoríos no cabe computar únicamente la extensión de su base territorial y la cantidad dineraria en que se arrendaba, pues, además de los ingresos cuya percepción se reservaba el señor -los luismos y derechos de entrada de las casas en el caso de Rafal-, el componente jurisdiccional, con todas sus implicaciones, incluídas las regalías, representaba un importante valor añadido. De hecho, el valor asignado a ambos núcleos señoriales, según la estimación realizada para el matrimonio de $\mathrm{D}^{\mathrm{a}}$ Jerónima en 1691, ascendía, en el caso de Rafal, a 30.000 libras; y en el de La Puebla, con los almarjales anexos, a 40.000, lo que supone una media en torno a las 20 libras por tahúlla. La valoración de las grandes heredades de huerta, sin embargo, aunque oscilaba ostensiblemente, raramente superaba las 15 libras por tahúlla. Eran las pequeñas fincas de huerta, y muy especialmente las dedicadas al

116. GIMÉNEZ LÓPEz, Enrique: Alicante en el siglo XVIII. Economía de una ciudad portuaria en el Antiguo Régimen, Alfons el Magnánim, Valencia, 1979, p. 432 
cultivo de moreral, las que sobrepasaban ampliamente en valoración media a todas las restantes, incluidos los dominios señoriales.

Finalmente, la situación patrimonial de los marqueses de Rafal una centuria después de la obtención del título revela un claro predominio de las rentas agrarias no señoriales. Frente a las aproximadamente 2.200 libras anuales que podían proporcionar los arrendamientos de La Puebla y de Rafal, las heredades del realengo contribuían a los ingresos de la casa nobiliaria con un valor liquido y en existencias trigueras cercano a las 4.300 libras. Esta supremacía era el lógico resultado de unas estrategias patrimoniales dirigidas a la acumulación de propiedades en el realengo que, en gran medida, estuvieron determinadas por las dificultades para acrecentar los dominios señoriales por vía matrimonial, pero también por la renuncia tácita a seguir la estela marcada por el artífice del marquesado cuando aleccionaba a sus herederos a emplear sus capitales en la fundación de nuevos pueblos, como él mismo había hecho en los casos de Rafa1, La Puebla y Benferri, tras la intentona frustrada de adquirir el de Redován ${ }^{117}$. Sin dejar de buscar consortes entre la nobleza señorial, los sucesores de D. Jerónimo, en efecto, no precisaban ya tanto ascender en el escalafón social mediante la incorporación de nuevos señoríos en el linaje familiar cuanto afianzar la situación económica mediante las inversiones que pudieran aportar mayor rentabilidad. Y, en esta orientación que parece presidir su estrategia patrimonial, la preferencia por hacerse con el dominio absoluto de una buena parte de las grandes heredades de la comarca representaba una opción llamada a convertirse en la pauta a seguir a finales del Antiguo Régimen, cuando, más que señorial, una buena parte de la nobleza era ya, ante todo, $\operatorname{propictaria}^{118}$.

\section{CUADRO VII}

Rentabilidad estimada de las propiedades rústicas de los marqueses de Rafal

$(1726 / 41)$

\begin{tabular}{|l|c|c|c|c|c|c|c|c|}
\hline $\begin{array}{l}\text { Heredades } \\
\text { /Señorios }\end{array}$ & $\begin{array}{c}\text { Extensión } \\
\text { (Thas) }\end{array}$ & $\begin{array}{c}\text { Valor 1691 } \\
\text { (Libras) }\end{array}$ & $\begin{array}{c}\text { Media } \\
\text { (Lib/ } \\
\text { tha) }\end{array}$ & $\begin{array}{c}\text { Renta } \\
\mathbf{1 7 2 6}\end{array}$ & $\begin{array}{c}\text { Renta } \\
\mathbf{1 7 2 9}\end{array}$ & Renta 1734/5 & $\begin{array}{c}\text { Renta } \\
\mathbf{1 7 4 1}\end{array}$ & $\begin{array}{c}\text { Media } \\
\text { (Lib/tha) }\end{array}$ \\
\hline Rafal & 1.500 & 30.000 & 20,0 & & & & & 0,54 \\
\hline La Puebla & 2.100 & 40.000 & 19,0 & & & & & 0,66 \\
\hline Era Alta & $130 / \mathbf{1 6 0}$ & 1.000 & 6,2 & & & & & 0,66 \\
\hline Arques & 500 & 4.000 & 8,0 & $38 \mathrm{cah}$. & $38 \mathrm{cah}+\mathrm{c}$ & $38 \mathrm{cah}+\mathrm{c}$ & & 0,63 \\
\hline Saavedra & $\mathbf{2 6 3 / 3 0 0}$ & 6.000 & 22,8 & $\mathbf{2 6} \mathrm{cah}$. & $24 \mathrm{cah} .+\mathrm{c}$ & $24 \mathrm{cah}+\mathrm{c}$ & & 0,78 \\
\hline Tell & $330 / \mathbf{3 6 0}$ & 1.200 & 3,3 & $\begin{array}{c}19,5 \\
\text { cah. }\end{array}$ & & 23 cah. $+\mathrm{c}$ & & 0,59 \\
\hline
\end{tabular}

117. BERNABÉ GIL, David: «La formación....», pássim.

118. De la extensa bibliografía sobre esta cuestión cabe destacar, para el marco territorial aquí tratado, MILLÁN Y GARCÍA-VARELA, Jesús: Rentistas y campesinos...; del mismo: El poder de la tierra, Instituto Juan Gil-Albert, Alicante, 1999; y, en colaboración con ZURITA, Rafael: «Élites terratenientes... ». Asímismo, los planteamientos, más generales, de RUIZ TORRES, Pedro: «La lï de la noblesa...»; y la rica información que sustenta los de CATALÁ SANZ, Jorge Antonio: Rentas y patrimonios.... 


\begin{tabular}{|c|c|c|c|c|c|c|c|c|}
\hline $\begin{array}{l}\text { Heredades } \\
\text { /Señorios }\end{array}$ & $\begin{array}{c}\text { Extensión } \\
\text { (Thas) }\end{array}$ & $\begin{array}{l}\text { Valor } 1691 \\
\text { (Libras) }\end{array}$ & $\begin{array}{c}\text { Media } \\
\text { (Lib/ } \\
\text { tha) }\end{array}$ & $\begin{array}{l}\text { Renta } \\
1726\end{array}$ & $\begin{array}{l}\text { Renta } \\
1729\end{array}$ & Renta $1734 / 5$ & $\begin{array}{c}\text { Renta } \\
1741\end{array}$ & $\begin{array}{c}\text { Media } \\
\text { (Lib/tha) }\end{array}$ \\
\hline D. Felipe & $770 / 822$ & 10.527 & 13,7 & & 35 cah. & 43 cah. & $\begin{array}{c}125 \mathrm{~L}+20 \\
\mathrm{cah}+\mathrm{c} \\
\end{array}$ & 0,36 \\
\hline $\mathrm{D}^{a}$ Inés & 600 & 8.000 & 13,3 & & & & $\begin{array}{c}130 \mathrm{~L}+26 \\
\mathrm{cah}+2 \mathrm{c}\end{array}$ & 0,60 \\
\hline Las Añoras & $140 / \mathbf{2 0 0}$ & 4.000 & 20,0 & & $160 \mathrm{~L}$ & $160 \mathrm{~L}$ & $200 \mathrm{~L}+\mathrm{c}$ & 1,14 \\
\hline Media Legua & $190+100$ & & & $29 \mathrm{cah}$ & $29 \mathrm{cah}+\mathrm{c}$ & $30 \mathrm{cah}+\mathrm{c}$ & & 0,86 \\
\hline $\begin{array}{l}\text { Casa Grande } \\
\text { Salin }\end{array}$ & 900 & 4.000 & 4,4 & & $1 / 7$ & $1 / 7$ & $\begin{array}{l}1 / 7+ \\
15 \mathrm{~L} \\
\end{array}$ & 0,09 \\
\hline $\begin{array}{l}\text { Casa Alta } \\
\text { Salinas }\end{array}$ & $400 / 800$ & & & & $1 / 7$ & $1 / 7$ & $1 / 7+5 \mathrm{~L}$ & 0,08 \\
\hline Guilarte & $500 / 700$ & & & & $1 / 7$ & & $1 / 7$ & 0,08 \\
\hline $\begin{array}{l}\text { Cueva } \\
\text { Fuerte }\end{array}$ & 1.000 & 1.500 & 1,5 & $45 \mathrm{~L}$ & & & $\begin{array}{l}1 / 7+ \\
35 \mathrm{~L} \\
\end{array}$ & 0,11 \\
\hline Las Sahurdas & 800 & 1.000 & 1,2 & & $\begin{array}{l}1 / 7+ \\
20 \mathrm{~L}\end{array}$ & $1 / 7+20 \mathrm{~L}$ & $\begin{array}{l}1 / 7+ \\
30 \mathrm{~L}\end{array}$ & 0,11 \\
\hline $\begin{array}{l}\text { Casa } \\
\text { Cascante }\end{array}$ & 1.050 & & & & & & $\begin{array}{l}1.140 \\
L+3 \mathrm{c} \\
\end{array}$ & 1,11 \\
\hline $\begin{array}{l}\text { Torre } \\
\text { Cascante }\end{array}$ & 1.000 & & & $60 \mathrm{~L}$ & & $80 \mathrm{~L}$ & $\begin{array}{l}1 / 7+ \\
35 \mathrm{~L}\end{array}$ & 0,11 \\
\hline $\begin{array}{l}\text { Cañada } \\
\text { Cascante }\end{array}$ & 150 & & & & & $10 \mathrm{~L}$ & & 0,01 \\
\hline $\begin{array}{l}\text { Palacios } \\
\text { Cascant }\end{array}$ & $193+130$ & & & & & & $240 \mathrm{~L}+\mathrm{c}$ & 0,77 \\
\hline Matanza & $3 / 4.000$ & 2.000 & 0,5 & & & $1 / 7$ & & 0,08 \\
\hline Correntías & 70 & 1.080 & 15,4 & & & & $60 \mathrm{~L}$ & 0,86 \\
\hline $\begin{array}{l}\text { Senda } \\
\text { Obispo }\end{array}$ & 16 & & & $40 \mathrm{~L}$ & $40 \mathrm{~L}$ & $40 \mathrm{~L}$ & & 2,50 \\
\hline $\begin{array}{l}\text { Hto. } \\
\text { Palmeras }\end{array}$ & & 3.000 & & & & & $30 \mathrm{~L}$ & \\
\hline Ac. Molina & 35 & & & $54 \mathrm{~L}$ & $54 \mathrm{~L}$ & $60 \mathrm{~L}$ & & 1,71 \\
\hline $\begin{array}{l}6 \text { Ac. } \\
\text { Huertos }\end{array}$ & $73 / 75$ & 3.700 & 50,0 & $225 \mathrm{~L}$ & $225 \mathrm{~L}$ & $245 \mathrm{~L}$ & & 3,31 \\
\hline
\end{tabular}

NOTAS:

Las cifras en negrita de la segunda columna, relativa al intervalo en que se mueven las distintas estimaciones sobre la extensión de las fincas, son las que se han adoptado como referencia para los cálculos recogidos en la cuarta y novena columna.

Las cifras en cursiva de la segunda columna se refieren a tahúllas de campo; en redonda, a tahúllas de regadío. La tahúlla (tha) de la huerta de Orihuela mide $1.185 \mathrm{~m} 2$

Abreviaturas: $L=$ Libras de moneda; $c a h=$ cahices de trigo; $c=$ cerdo

Fuentes: ACO: Protocolos de Andrés Ximénez, 1691, ff. 258 y ss; AHO: Protocolos de Bernabé Aniorte, 1726; ff. 64-70v, 162-175v, 178v-200v, 297-218v; Protocolos de Bautista Ramón, 1729, ff. 271-273, 285297, 304-309, 335-340v, 379-384v, 390-392; Protocolos de Bautista Alemán, 1734, ff. 100-101, 126-127v, $132-136,155-156 \mathrm{v}, 160-161 \mathrm{v}, 170-171 \mathrm{v}, 182-183 \mathrm{v}, 188-189 \mathrm{v}, 195-198 \mathrm{v}, 200-205 \mathrm{v}$; Protocolos de Bautisia Alemán, 1735,» ff. 5I-52, 153-154v; Protocolos de Josep Martínez de Rodrïguez, 174I, ff. 1-140v;. 


\section{APENDICE DOCUMENTAL}

Escritura de establecimiento de tierras y casa en Rafal, otorgada por D. Gaspar Rocamora, 1643.

Sit omnibus notum com lo Illustre Don Gaspar de Rocamora Garcia de Lasa, Cavaller del habit de Sent Jaume, Baro de la Puebla, Marques de Rafal, de la ciutat de Oriola habitador, atrobat en lo present lloch de Rafal, en nom de senyor directe de les tafulles y cassa infraescrites eis melioribus via modo et forma etc gratis etc cum $p$ (rese)nti etc. estableix ac in emphiteosim perpetuum concedeix lliura seu quasi a Frances Masquefa llaurador y a Salvadora Crespo coniunges de dit lloch de Rafal habit(ador)s que son presents rebents y acceptants e als seus trenta tafulles y mija de terra situades en la horta de dit lloch de Rafal, so es les vint y sis y mija de terra blanca que afronten de part de llevant ab tafulles de Francisco Hernandes, de ponet ab tafulles de Don Thomas Maca de Licana, de tremontana ab tafulles de dit Marques y de part de mijorn ab arrova de Sent Berthomeu y les restants quatre tafulles de terra plantades morerals afronten de part de llevant y tremontana ab tafulles de dit Marques de ponent ab tafulles de Miquel Soriano y de part de mijorn ab dita arrova. Item establex a dits coniunges una casa situada e posada en lo dit lloch segons que afronta de part de llevant ab casa de Francisco Hernandes de ponent ab moreral de dit Marques de tremontana ab tafulles de dit Marques y de part de mijorn al lo forn carrer en mig. Aquest empero establiment de dites casa y tafulles los fa tantum en quant lo util domini de aquelles reservantse dit Marques vers si y los seus lo domini directe de dites casa y tafulles y ab les pactes y condicions seguents y no sens aquells aliter nec alias.

[1] Primerament ab pacte y condicio que per dita casa sien tenguts y obligats les dites coniunges y sos successors de donar y pagar al dit Illustre Marques e als seus cascun any vint sous y una gallina y per cascuna tafulla de terra de les desus dites axi de les plantades com de les de terra blanca nou sous censals vendals e annuals fadigues y lloismes ab tot altre plen dret emphiteotich e dret de rebre aquells segons forma de fur de Valencia sots directa senyoria de dit Marques e dels seus pagadors tots anys lo dia e festa de Sent Miquel del mes de setembre comensant a fer la primera paga lodia e festa de Sent Miquel del mes de setembre primer vinent del present e corrent any y de alli avant consecutivament en dit termini perpetuament axi per la dita casa com per les dites tafulles.

[2] Item ab pacte y condicio que lo dit Marques senyor directe desus dit los establex dites casa y tafulles per franques e quites de tota altra naturalea de cens e per dita rao los fa e ferma carta de indempnitat.

[3] Item ab pacte y condicio que los dita coniunges y los seus sien tenguts y obligats a millorar y no gens a pijorar dites casa y tafulles a us y costum de bons adquiridors e censaters sots pena de comis.

[4] Item ab pacte y condicio que ultra dels dits vint sous y una gallina de fadiga y lloysme que es lo cens que cascun any han de pagar per dita casa hajen de donar y pagar al dit Marques per aquella la tersera part de lo que tasaran dos bons homens 
experts mestres de obres de vila nomenadors per les parts la qual dita tersera part tinguen obligacio de pagar en la forma y manera que es contendra en lo acte de obligacio que dits coiunges han de fer y fermar en favor de dit Illustre Marques com les altres dos parts aquell los fa solta de aquells per la anua respondio que cascun any le han de fer.

[5] Item ab pacte y condicio que si les dites coiunges o los seus per algun temps voldran vendre dites tafulles o casa hajen y sien temguts y obligats de presentar primerament al dit Marques e als seus la fadiga de trenta dias conforme dits furs e haguda llicencia de aquella ab la solempnitat acostumada per apoderles vendre hajen de pagarli lo lloisme de la casa que vendran que es la deena part del preu en que la vendran e aso sots pena de comis dels dits bens de tal manera que la util senyoria sia ab efecte consolidada ab la directa y los dits bens adjudicats al dit Marques senyor directe ensemps al los fruits que y hi aura en les dites tafulles.

[6] Item ab pacte y condicio que en cas que hauran obtes la dita llicencia per a poder vendre los dita bens y pagat lo dit lloisme puxen fer la dita venda salvant empero y reservant al dirt Marques senyor directe y als seus lo dit cens fadiga lloisme e directa senyoria sots la dita pena de comis.

[7] Item ab pacte y condicio que no appellaran ni puxen appellar per raho de les desus dites tafulles y casa altres patrons ni senyors directes ni a altres jutges si no sera al dit6 Marques verdader senyor directe de dits bens e als seus sots la dita pena de comis.

[8] Item ab pacte y condicio que no pujen dits coniuges ni los seus vendre dits bens ni part de aquells a persona alguna forastera ni extrangera del present lloch de Rafal si no sera als vehins y habitadors de dit lloch de Rafal presehint dita llisensia sots la dita pena de comis.

[9] Item ab pacte y condicio que dits coniuges ni los seus no puxen arrancar arbres alguns de les dites terres ni fer mudaments nous en aquelles ni traure altres portes de nou al carrer ni a altres parts en dita casa sens presehir expresa llicencia e facultat del dit Marques senyor directe sots la dita pena de comis.

[10] Item ab pacte y condicio que dits coniuges e los seus juntament ab les demes vehins del dit lloch que son e seran hereters de terres del dit lloch y los eus sien tenguts y obligats a mondar a comunes despeses de aquells la acequis appellada de Almoradi y arrova de Sent Berthomeu pagant cascu per les tafulles que possehira y tot lo demes que convindra mondar en los demes edificis de brasals asarps y escorredors y altres edificis de la horta de dit lloch y no gens a despeses del dit Marques senyor directe ni dels seus.

[11] Item ab pacte y condicio que si sucsehira cas de traure de nou alguns alguns edifisis per a benefisi de hereters si ay aja de ser a propries y comunes despeses dels hereters de aquelles y no gens del dit Marques senyor directe ni dels seus com axi matex de mudaments de edifisis.

[12] Item ab pacte y condicio que si per algun temps los dits coniuges o los seus voldran edificar y obrar en dits llochs algunes cases noves per a si o per a els seus sien tenguts y obligats de rebre aquelles de dit Marques senyor directe e dels seus per esta- 
bliment ab la matexa respondio de vint sous y una gallina fadigues y lloismes ab tota altra directa senyoria del dit Marques y dels seus sots la dita pena de comis.

[13] Item ab pacte y condicio que dits coniuges ni els seus no pujen ser senyors utils de dits bens sino sera estant y habitat en dit lloch de Rafal y no de altra manera sots la dita pena de comis.

[14] Item ab pacte y condicio que los dits coniuges ni els seus no pujen en manera lguna fer cambis alguns de dites terres ni casa sens presehir llicencia y expres consentiment de dit Marques senyor directe y dels seus y presehint dita llicencia ho pujen fer pagant a dit senyor directe y als seus lloisme de totes les cantitats de tornes e mes values que es tornaran en tals cambis los uns als altres sots la dita pena de comis.

[15] Item ab pacte y condicio que si lo dit Marques senyor directe e los seus successors faran y construhiran algun moli fariner en dit lloch o prop de aquell com no diste del de dit lloch mes de mija llegua tinguen obligacio dits coniuges y los seus llevar a moldre a dit moli tots los grans que colliran en dites terres que voldran moldre puis dits grans se an de collir en dites terres e aso sots pena de pagar altra vegada la maquila del que constara haver molgut fora dit moli del dit Marques.

[16] Item ab pacte y condicio que dits coniuges ni els seus ni demes pobladors vasalls ni terratinents de dit lloch no pujen donar los dits bens establits per donacions testaments codicils e ultimes e darreres voluntats a persones de religio ni ecclesiastiques confraries ni llochs sants ni que en manera alguna puxen entrar en ma morta sots pena de comis.

[17] Item ab pacte y condicio y no en altra manera aliter nec alias que si dits coniuges o algu de aquells eo dels seus successors presents y esdevenidors en dit establiment in perpetuum lo que Deu no permeta encorreran in crime de lesa Maiestatis divina o humana o en cas de Inquisicio o en altre qualsevol per lo qual cayga en cas de confiscacio de bens un dia abans de cometre ni ymaginar dit cas sia vist haver caygut y encorregut en pena de comis y restar les haziendes dels tals consolidades ab la directa senyoria.

[18] Item que dins sinch anys apres la confectio del present en avant continua y peremptoriament contadors ajen de ajustarse dits coniuges ab los demes vehins y pobladors de dit lloch y tots en comu fer acte publich reconexen la dita directa senyoria y prestar lo homenatge de fidelitat a dit Marques y de guardar y observar los capitols y ordinacions del present establiment en forma y ab le solempnitat de dret deguda.

[19] Item ab pacte y condicio que en lo dit acte y en virtut de dit jurament hajen de prometre y obligarse que no nomenaran officials so es Justicia y Jurats y les demes que se offeriran per a lo regiment y govern del dit lloch sino que donaran memoria triplicada al dit Marques de les persones abtes y convenients per a dits offisis per a que de aquelles aja de nomenar dits officials se la reserva per si y en son poder y si lo contrari sera fet sia nulle y ningu.

[20] Item ab pacte y condicio que los dits coniuges y los seus tingan obligacio de anar a coure lo pa al forn que dit Marques te y tindra en dit lloch y que ningu de aquells puja tenir forn en dit lloch sens la sua llicencia exprpessa sots pena de comis. 
[21] Item ab pacte y condicio que dits coniuges ni els seus no pujen tenir tenda ni taverna en dit lloch sino solament la persona o persones que la hauran arrendat del dit Marques y que no pujen vendre sos fruits per menut sots pena de sexanta sous so es de vi y oli y de les demes coses que es venen en la tenda.

[22] Item ab pacte y condicio que dits coniuges ni els seus no pujen venir be ara ni per ningun tenps en imposar sises imposicions pechos ni estanchs alguns encara que sia presehint llicencia del dit Illustre Marques.

[23] Item ab pacte y condicio que si dits coniuges o alguns de aquells mudaran son domicili y alberch a altra part fora del dit lloch y per dita raho les dites casa y tafulles ab lo present les son establides vindran a menis que pujen ser compellits per dit Illustre Marques a que vinguen a viure y habitar al dit e present lloch de Rafal y a conrrear y sustentar les dites caa y tafulles que tindran y si ho dexaran de fer presehint manament juridich que es puja instar contra aquells y los seus successors execucio per a que paguen de sos propris bens que tindran les pijores y danys que les terres y casa tindran y les que es seguiran y se hauran seguit en aquelles fins tant se trobe persona a qui sien establides dites casa y tafulles per lo matex preu que aquells les tenen de present y si se esdevendra que se establisen per mes preu no puguen pretendre cosa alguna en lodit augment.

[24] Item ab pacte y condicio y no sens aquell que les causes plets y litigis que es suscitaran y mouran entre dits coniuges los seus y demes vehins y habitadors de dit lloch se ajen de decidir y determinar en primera instancia so es per lo Asessor nomenador per lo Justicia qu hui es o per temps sera del dit Marquesat y que la primera appellacio sia per a davant del matex Justicia ab altre Asessor nomenador per aquell y que la tersera sia per a davant sa senyoria y son Asessor General de dit Marquesat de tal manera que dits pobladors no pujen intentar actio ni demanda alguna davant de altre jutge en primera segona ni ultima instancia si no sera davant los dits jutges y si lo contrari sera fet encorrega el que proclamara a altre jutge en perdicio de la causa que intentara y ultra de dita pena en altres a arbitre de sa senyoria reservat.

$\mathrm{Y}$ ab tot los desus dits pactes y condiciones y per la dita tersera part en que dita casa sera estimada y ab lo dit cens fadiga lloisme ab tot altre plen dret emphiteotich dit e present establiment et in emphiteosim concessionem de les dites terres y casa los fa en dit nom cum omnibus suis juribus etc. tantum con respecte del util domini de dites tafulles y casa com lo directe domini es reserve dit Illustre Marques ver si y los seus en dit Marquesat successors presents y esdevenidors presentis instrumento contentis non obtantibus etc. De quibus etc et quigus etc instituen etc conffitens etc ad habendum etc segons forals disposicions del present Regne de Valencia y ab les solemnitats llegitimament requisites y no sens aquelles aliter nec alias exceptis clericis nisi etc nisi dicti clerici etc salvis tamen etc. Promitens etc. e vole ser tengut de forma y legal evictio Ita quod si forte etc una cum omnibus dampnis etc super quibus credantur etc pro quibus etc obligavit etc e los dits Frances Masquefa y Salvadora Crespo coniuges com estiguesen presents rebents y acceptants dit e present establiment et in emphiteosim concessionem de les desus dites casa y tafulles ab les pactes y condicions carrechs y obligacions desus dits amb o simul et in solidum gratis et cum presenti etc prometen y 
se obliguen al dit Illustre Marques en dit nom que es present rebent y acceptant y als seus successors absents et not. tamen etc fer y cumplir tots los dits pactes y condicions carrechs y obligacions segons en dits capitols se conte y a dits coniuges los pertany. Pro quibus etc obligen amb o similitem solidum etc renuncien a la de partida actio et nova e vella constitucions a la Epistola del divi Adria Legi que ac foro Valenciae de principali prius conveniendo etc et legi de queritur ff. comodati et omni alii juri aut foro premisis obtantibus etc et juri etiam dicenti generalment renunciacionem non valere nisi in expresatis e la dita Salvadora Crespo certificada etc jura et renuncia al Velle y a doti que etc et omni alii muliebri auxilio in favorem mulieriem quomodo libet introdicto de quibus etc. Actum Rafal etc testi predicti.

(AHO: Protocolos de Juan Liñan, 1642-1643, ff. 456-465, escritura de 24 de enero de 1643) 